\title{
Identification of disease markers in human cerebrospinal fluid using lipidomic and proteomic methods
}

\author{
Alfred N. Fonteh ${ }^{\mathrm{a}, *}$, Robert J. Harrington ${ }^{\mathrm{a}}$, Andreas F. Huhmer ${ }^{\mathrm{b}}$, Roger G. Biringer ${ }^{\mathrm{b}}$, \\ James N. Riggins ${ }^{\mathrm{a}}$ and Michael G. Harrington ${ }^{\mathrm{a}}$ \\ ${ }^{a}$ Molecular Neurology Program, Huntington Medical Research Institutes, Pasadena, CA 91101, USA \\ ${ }^{\mathrm{b}}$ Thermo, San Jose, CA 95134, USA
}

\begin{abstract}
Lipids comprise the bulk of the dry mass of the brain. In addition to providing structural integrity to membranes, insulation to cells and acting as a source of energy, lipids can be rapidly converted to mediators of inflammation or to signaling molecules that control molecular and cellular events in the brain. The advent of soft ionization procedures such as electrospray ionization (ESI) and atmospheric pressure chemical ionization (APCI) have made it possible for compositional studies of the diverse lipid structures that are present in brain. These include phospholipids, ceramides, sphingomyelin, cerebrosides, cholesterol and their oxidized derivatives. Lipid analyses have delineated metabolic defects in disease conditions including mental retardation, Parkinson's Disease (PD), schizophrenia, Alzheimer's Disease (AD), depression, brain development, and ischemic stroke. In this review, we examine the structure of the major lipid classes in the brain, describe methods used for their characterization, and evaluate their role in neurological diseases. The potential utility of characterizing lipid markers in the brain, with specific emphasis on disease mechanisms, will be discussed. Additionally, we describe several proteomic strategies for characterizing lipid-metabolizing proteins in human cerebrospinal fluid (CSF). These proteins may be potential therapeutic targets since they transport lipids required for neuronal growth or convert lipids into molecules that control brain physiology. Combining lipidomics and proteomics will enhance existing knowledge of disease pathology and increase the likelihood of discovering specific markers and biochemical mechanisms of brain diseases.
\end{abstract}

Keywords: Lipidomics, phospholipidomics, sphingolipidomics, cholesterol, proteomics, mass spectrometry, electrospray ionization, phospholipases, enzymes, lipoproteins, cytochrome P450, acetylhydrolases, fatty acids, eicosanoids, secretion, ion channels, receptors, inflammation, oxidation, cerebrospinal fluid, brain, neurological diseases

\author{
Abbreviations used: \\ AA, arachidonic acid \\ Apo, apolipoprotein \\ APCI, atmospheric pressure chemical ionization \\ $\mathrm{BBB}$, Blood brain barrier \\ CDP, cystidine diphosphate \\ $\mathrm{CSF}$, cerebrospinal fluid \\ COX, cyclooxygenase \\ CYP, cytochrome $\mathrm{P}$ \\ ESI, electrospray ionization \\ ESI EPA, eicosapentaenoic acid
}

\footnotetext{
*Corresponding author. Tel.: +1 626795 4343; E-mail: afonteh@ hmri.org.
} 
(EPA) DHA, docosahexaenoic acid

(DHA) HETES

HDL, low density lipoprotein

IP, inositol phosphate

LC-MS ${ }^{2}$, liquid chromatography tandem mass spectrometry

LDL, low density lipoprotein LO, lipoxygenase

LT, leukotriene

PA, phosphatidic acid

PAF, platelet-activating factor

PAFA, platelet-activating factor acetylhydrolase

PC, phosphatidylcholine

PE, phosphatidylethanolamine

PhosGl, phosphatidylglycerol

PG, prostaglandin

PI, phosphatidylinositol

PIP, phosphatidylinositol phosphate

PL, phospholipase

$\mathrm{PLA}_{2}$, phospholipase $\mathrm{A}_{2}$

PLC, phospholipase C

PLD, phospholipase D

PS, phosphatidylserine

PUFA, polyunsaturated fatty acid

SRM, selected reaction monitoring

pAD, probable Alzheimer's disease

PD, Parkinson's disease

SRM, selected reaction monitoring

\section{Glossary}

Lipidome- All known lipids, includes phospholipids, fatty acids and cholesterol. The study of structure, biosynthesis and function of all lipids is lipidomics.

Phospholipidome- All known phospholipid classes, subclasses and molecular species. The study of structure, cellular distribution, biosynthesis and function of phospholipids is phospholipidomics.

Sphingolipidome- All known sphingolipid classes and molecular species. The study of structure, cellular distribution, biosynthesis and function of sphingolipids is sphingolipidomics.

\section{What are lipids and why are they important in brain function?}

Lipids are organic compounds with long chain hydrocarbon molecules that are soluble in organic solvents but not soluble in water. Lipids are derived from living organisms; some examples of lipids include long chain hydrocarbons, alcohols, aldehydes, fatty acids, their derivatives (glycerides, wax esters, phospholipids, glycolipids, sulfolipids, and fatty acid esters), fat soluble vitamins (A, D, E and K), carotenoids and sterols. Lipids are usually subdivided into neutral or polar lipids and are now classified into eight categories based on hydrophobic and hydrophilic composition [68]. About half of the dry weight of the brain is made of lipids. Lipids are important in many brain functions including membrane composition, signal transduction, and biological messenger functions [18,39,40,61,67,69,88, 206,221]. Thus, changes in the concentrations of brain lipids may reflect physiopathologic processes.

One class of lipids proposed to be important in brain function is the polyunsaturated fatty acids (PUFAs). PUFAs are released from phospholipids by lipases to carry a myriad of biological functions. For example, arachidonic acid (20:4, n-6) can be released and subsequently converted to eicosanoids by cycloxygenases (COX), epoxygenases, lipoxygenase (LO) in combination with prostaglandin or leukotriene synthases $[6,160$, 180,190,195]. Eicosanoids act on specific receptors or ion channels to influence physiological processes such as sleep and pain [94,95]. Likewise, several neurosteroids derived from cholesterol have been shown to have important physiologic functions in the brain [10, $99,116,170,213]$. In addition to providing signaling molecules, lipids are the building blocks of cell membranes that confer structure and insulation to nerve cells and are a major reservoir of stored energy. With these important functions, changes in their amounts or defects in lipid metabolic pathways can have a significant impact on brain function. Therefore, an accurate measure of lipid concentrations in the central nervous system is needed for understanding their role in the pathology of diseases.

Lipids encompass a range of structurally dissimilar molecules consisting of several isomers that are difficult to isolate. Lipids do not easily ionize and 
upon collision-induced dissociation, fragment into ions that can not be useful fingerprints for distinguishing the thousands of molecular species found in cells. No single ionization method can be used for all lipid classes. Moreover, differently charged headgroups in lipids make some lipids easy to ionize in the positive mode while others are better measured in the negative mode. However, recent advances in mass spectrometry have made it possible to use electrospray ionization (ESI) $[90,105,129,133]$ with negative or positive ions under atmospheric pressure conditions to measure several molecular species of lipids. Combined with liquid or gas chromatography, hundreds of lipid molecular species can now be identified.

\section{Structures of lipids detected in human brain and CSF and their biosynthetic pathways}

\subsection{Phospholipidome}

The phospholipidome consists of the major polar lipid class found in mammalian cells and the study of their structure, biosynthesis and catabolism is henceforth referred to as phospholipidomics. Structurally, phospholipids are composed of a glycerol backbone to which is esterified a fatty acid at the $s n-1$ and $s n-2$ carbon and a phosphor-headgroup moiety at the $s n-3$ position. When the headgroup is choline, ethanolamine or serine, the phospholipids are known as phosphatidylcholine (PC), phosphatidylethanolamine (PE) or phosphatidylserine, respectively (Fig. 1A). Phosphatidylinositol (PI) and phosphatidylglycerol (PhosGl) are formed when inositol and glycerol are the headgroups, respectively (Fig. 1A). Phosphatidic acid (PA) and diphosphatidylglycerol (cardiolipin) are other important phospholipids classes with structures depicted on Fig. 1.

Phospholipids are further divided into subclasses based on the type of linkage of fatty acids at the $s n-1$ position. In ester lipids, fatty acids are attached via 1 -acyl bonds while for ether lipids or plasmalogens, fatty acids at the $s n-1$ position are linked via 1-alkylor 1-alk-1-enyl- bonds (Fig. 1B). 1-Acyl-, 1-alkyl or 1-alk-1-enyl- subclasses are predominant in PC and PE while diacyl-linked subclasses comprise most of PI, PS and PG found in cells. Ethanolamine plasmalogens are abundant in myelin sheath and changes in their composition are proposed for several diseases including AD. Choline plasmalogen is a precursor of the potent biological mediator known as platelet-activating factor (PAF) or 1-alkyl-2-acetyl-sn-glycero-3-phosphocholine. PAF is a mediator of hypersensitivity, acute inflammation, anaphylactic shock, platelet aggregation and serotonin release $[31,37,149,152]$. Bazan et al. have proposed that PAF is important in brain plasticity [12].

In most phospholipids, the fatty acid at the $s n-1$ position is palmitic (16:0), stearic $(18: 0)$ or oleic acid (18:1) while either a saturated, unsaturated or a polyunsaturated fatty acids (PUFAs) can be found at the $s n-2$ position of the glycerol backbone. In certain classes and subclasses found in cells or tissues, PUFAs are the major fatty acids at the $s n-2$ position. This distribution gives rise to subclasses of lipids that are targeted for the release of PUFAs and the generation of specific lipid mediators and signaling molecules. An example is 1-alkyl-2-arachidonoyl-sn-glycero-3phosphocholine, the precursor of platelet activating factor and leukotrienes [77,122]. The incorporation of PUFAs into phospholipid subclasses is highly choreographed such that most PUFAs are initially incorporated into 1,2-diacyl phospholipids subclasses before they are remodeled into the ether-linked phospholipids classes by coenzyme A (CoA)-dependent or CoA-independent transacylase activities [73,84,126, 165,167].

Phospholipids are not only variable in their head groups, fatty acids and bond profiles on the glycerol backbone, but they are asymmetrically distributed within lipid bilayers of cells. This molecular diversity results in hundreds of molecular species in a given cell and theoretically thousands of species in mammals. Even more intriguing is the fact that different organelles may be enriched with specific lipid classes or subclasses. These distributions are unique in establishing the functions of different organelles by influencing membrane fluidity or generating signaling molecules in specific sites when cells are stimulated.

Phospholipids are synthesized when cystidine diphosphate (CDP)-activated polar headgroups are attached to PA (1,2-diacyl-sn-glycerol-3-phosphate) or when CDP-activated diacylglycerol (DAG) is attached to polar headgroups. For example, PC or lecithin is synthesized when choline is phosphorylated by cholinephosphotransferase [106] and then coupled to CDP prior to attachment to PA. Cholinephosphotransferase catalyzes the final step in the synthesis of $\mathrm{PC}$ via the Kennedy pathway by transferring phosphocholine from CDP-choline to DAG [98]. For PE biosynthesis, ethanolaminephosphotransferase catalyzes a similar transfer of ethanolamine with CDPethanolamine as the intermediate. PC can also be ob- 
(A)<smiles>[R]C(=O)O[C]C(COP(=O)([O-])OCC[NH3+])OC([R])=O</smiles>

PC (Phosphatidylcholine or 1,2-Diacyl-snglycero-3-phosphorylcholine or lecithin)<smiles>[R]C(=O)OCC(COP(=O)([O-])OCC([NH3+])[NH2+]C(=O)[O-])OC([R])=O</smiles>

PS (Phosphatidylserine or 1,2-Diacyl-snglycero-3-phosphorylserine)<smiles>[R]C(=O)OCC(COP(=O)([O-])O)OC([R])O</smiles>

PA (Phosphatidic acid or 1,2-Diacyl-sn-glycero-3 -phosphate)<smiles>[R]OC1COC(=O)CC(OC([R])=O)COP(=O)(O)OC1</smiles>

PG (Phosphatidylglycerol or 1,2-Diacyl-sn-glycero-3phosphoryl-1 -sn-glycerol)<smiles>[R]COP(=O)([O-])OCC(COC([R])=O)OC([R])=O</smiles>

PE (Phosphatidylethanolamine or 1,2-Diacyl-snglycero-3-phosphorylethanolamine)

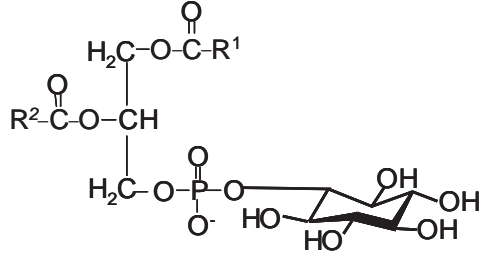

PI (Phosphatidylinositol or 1,2-Diacyl-snglycero-3-phosphorylinositol)

(B)

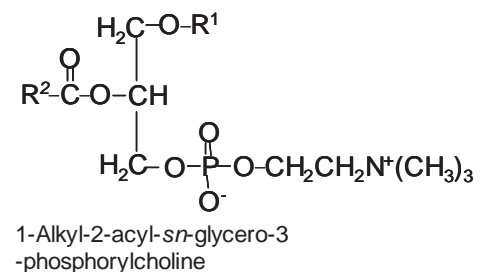
-phosphorylcholine<smiles>[R]C(=O)OCC(COC([R])[R])OCC(COP(=O)([O-])O)OCC(=O)OC([R])=O</smiles>

Cardiolipin (diphosphatidylglycerol)

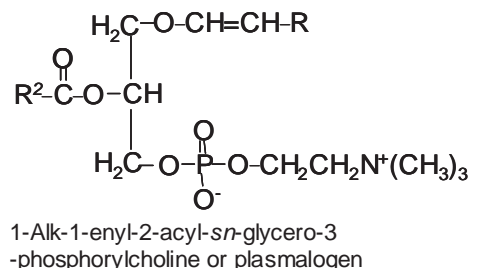

Fig. 1. Structure of phospholipids- Ester-linked phospholipids (A) and ether-linked phospholipids (B). Stereospecific numbering (sn) system of nomenclature for the glycerol backbone is indicated while $\mathrm{R}^{1}$ and $\mathrm{R}^{2}$ denote fatty acyl moieties. The classification of phospholipids into subclasses (1-acyl-, 1-alkyl- or 1-alk-1-enyl-) is shown by the fatty acyl-bond at the sn-1 position of glycerol.

tained when PS is decarboxylated to PE followed by Nmethylation of PE by S-adenosylmethionine-dependent methyl transferase [216]. Base exchange reactions when ethanolamine is exchanged for serine in PE results in PS biosynthesis. Similar to PC biosynthesis, PI is formed when 1,2 DAG is activated by CDP followed by condensation with myo-inositol. PI can undergo a series of phosphorylations catalyzed by various PI-kinases to form phosphopolyinositides. PIP 2 is an example of phosphorylated PI that has been well characterized and been shown to be a signal for cell growth, differentiation and synaptic vesicle formation [59,177].

The phospholipidome undergoes dynamic remodeling of fatty acids and phospho-headgroups under resting conditions and this remodeling process is enhanced when cells are stimulated and decreased when cells are undergoing apoptosis [79,84]. Examples of enzymes that catabolize phospholipids and the products they generate are listed on Table 1 . The major enzymes that modify phospholipids include phospholipases (PLA $1, \mathrm{PLA}_{2}$, PLC, PLD), acyl transferases and PI specific kinases. Phospholipases hydrolyze ester 


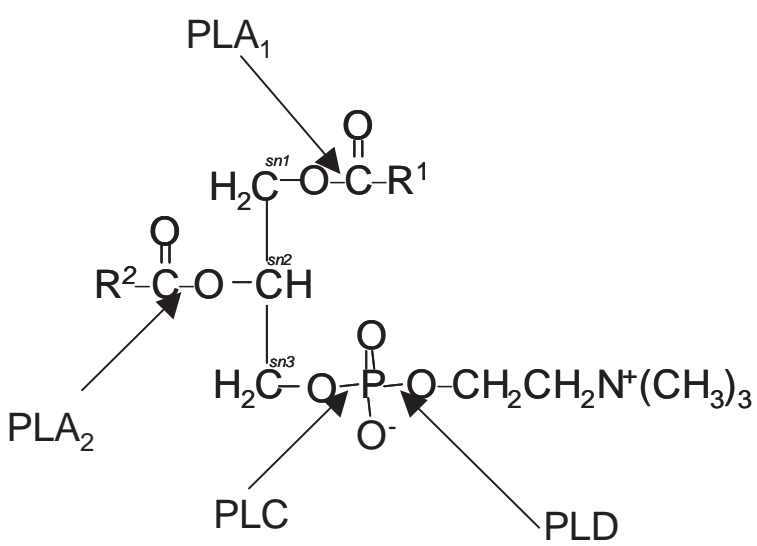

Fig. 2. Sites of action of phospholipases on phosphatidylcholineThe major groups of phospholipases include PLA 1, PLA $_{2}$, PLC and PLD. Products of these enzyme activities and their relevance to the brain are shown on Table 1 .

bonds shown on Fig. 2. Many isoforms of PLA 2 that differ in structure, substrate specificity, requirements for calcium ions, mode of activation and cellular localization have been cloned and described in various mammalian cells [123]. Several PLA 2 isoforms have been characterized in the brain [73,204]. One $\mathrm{PLA}_{2}$ isoform $\left(\mathrm{cPLA}_{2}\right)$ co-localizes with reactive astrocytes and glial cells and is involved in neurodegeneration [47]. Various PLC isoforms are involved in the generation of DAG and $\mathrm{IP}_{3}$ in the rat and human brain [183,192]. Two isoforms of PLD $\left(\mathrm{PLD}_{1}\right.$ and $\left.\mathrm{PLD}_{2}\right)$ generate signaling molecules in the brain and involved in the generation of choline required for acetylcholine biosynthesis [230]. PLD isoforms are implicated in neural outgrowth and hormonal/stress signaling [219,220,236]. Lysophospholipids generated by the action of $\mathrm{PLA}_{2}$ can accept acyl groups from other phospholipids in a reaction catalyzed by lysolecithin-lecithin-acyltransferase (LLAT) [203]. Other CoA-dependent and -independent remodeling of PUFAs are responsible for the buildup of PUFAs in ether-linked phospholipids [82,121,165]. Lecithin cholesterol acyltransferase (LCAT), a protein with both lipase and transferase activity transfers fatty acids from lecithin to cholesterol [1,110]. LCAT is associated with lipoproteins that are involved in the transport of lipids from the liver to organs and vice versa. Although not recognized as the major pathway by which cholesterol is excreted from the brain, lipoprotein-mediated transport is important in neural outgrowth and may be the major transcellular transport mechanism within the brain.

\subsection{Sphingolipidome}

The sphingolipidome is a subset of the phospholipidome consisting of sphingomyelin and glycosphingolipids (cerebrosides, sulfatides, globosides and gangliosides). Sphingolipids are composed of a polar headgroup and two non-polar tails (Fig. 3). A long chain amino alcohol known as sphingosine is linked via an amine and a long chain fatty acid is attached to carbon2 to yield ceramide. Sphingolipids are components of membranes found mainly in myelin sheaths. The major route of sphingolipid formation is the transfer of phosphorylcholine from PC to ceramide by sphingomyelin synthase (Fig. 3). Sphingomyelins are important in nerve cell membranes where very long chain saturated and monounsaturated fatty acids are the main $\mathrm{N}$-acylated molecules at carbon- 2 of sphingosine [96, $142,188]$.

The action of sphingomyelinase on sphingomyelin forms choline and ceramide. Ceramide can be further broken-down to sphingosine by ceramidase or can be converted to glucosylcerebroside by glycosyl ceramide synthase [179,184] (Fig. 3). Sphingosine phosphate and related molecules have recently been shown to regulate apoptosis $[128,153]$. Although these novel mediators have not been characterized in the brain, their presence may account for brain diseases that are known to result from defects in sphingolipid biosynthesis. Thus, one may postulate that changes in sphingosine phosphate levels in the neurodegenerative brain may be early indicators/biomarkers of brain atrophy.

In summary, the phospholipidome provides structure, is the precursor of signaling molecules and plays an important role in the formation of vesicles required for neurotransmitter release and the transport of metabolites. These important functions make it necessary to study the composition of brain phospholipidome because early changes are possible events in brain diseases.

\subsection{Cholesterol and hormones}

The brain is a very rich source of cholesterol and is estimated to represent $25 \%$ of total cholesterol in humans [60]. Although it is known that a major portion of this cholesterol is localized in myelin sheaths, little is known about the metabolic pathways that control this vast reservoir of cholesterol. Brain cholesterol is mainly produced by de novo synthesis (Fig. 4) and is segregated from plasma cholesterol by the blood brain barrier (BBB). Homeostatic control of brain cholesterol 
Table 1

Some enzymes that modify phospholipids, their products and functions in CNS

\begin{tabular}{|c|c|}
\hline Enzymes & Lipid substrates and products \\
\hline $\mathrm{PLA}_{2}$ & $\begin{array}{l}\text { Hydrolyzes the ester bond at the } s n-2 \text { position of phos- } \\
\text { pholipids (Fig. 2) to release free fatty acids (FFA) and } \\
\text { lysophospholipids. For example, PC is hydrolyzed to } \\
\text { LPC and FFA or PA hydrolyzed to LPA and FFA. }\end{array}$ \\
\hline PLC & $\begin{array}{l}\text { Hydrolyses phospholipids to DAG and phospho- } \\
\text { headgroup moiety, e.g. } \mathrm{PI}(4,5) \mathrm{P}_{2} \text { to DAG and } \\
\mathrm{I}(1,4,5) \mathrm{P}_{3}[21]\end{array}$ \\
\hline PLD & $\begin{array}{l}\text { Releases PA and free headgroup from phospholipids } \\
\text { (Fig. 2). An example is the release of choline from } \\
\text { PC. }\end{array}$ \\
\hline Lysophospholipase & $\begin{array}{l}\text { Glycerophosphate and free fatty acids [218]. Im- } \\
\text { plicated in ether lipid formation by brain micro- } \\
\text { somes [229] and anandamide biosynthesis [205] }\end{array}$ \\
\hline PI kinase or PIP & Phosphorylate $\mathrm{PI}$ to form $\mathrm{PI}(4) \mathrm{P}$ and $\mathrm{PI}(4) \mathrm{P}$ to \\
\hline kinases and PITP & $\mathrm{PI}(4,5) \mathrm{P}_{2}$. PITP is involved in membrane remodeling. \\
\hline
\end{tabular}

Importance of products

If the FFA is a PUFA, it may be a substrate of COX, CYP or LO. $\mathrm{PLA}_{2}$ activity is implicated in endocytosis, fusion and membrane structure and asymmetry, neurodegenerative diseases and autistic disorders [20,73,204,208].

Important in vesicle priming and synaptic vesicle docking [52,59]. DAG activates PKC and/or PKA while IP3 induces intracellular calcium release [22].

Implicated in synaptic vesicle fusion. PA promotes exocytosis, phagocytosis, membrane trafficking and cytoskeletal structure [48,51,62,147,219,220]. Headgroup such as choline can be used for neurotransmitter biosynthesis.

Important in signal transduction [174,210,218].

Required for synaptic vesicle formation, fusion, trafficking and exocytosis $[49,50]$ involves biosynthesis and cytochrome P450 (CYP)mediated excretion with $24 \mathrm{~S}$-hydroxycholestrol as the major product [24,28]. Cholesterol serves several important functions in the brain. First, cholesterol helps maintain brain structure and is important in controlling lipid fluidity and the transport or permeability of ions and metabolites. Second, cholesterol provides the necessary insulation to neurons that allows efficient propagation of an action potential. Third, cholesterol is needed for the growth and development of neurons. Fourth, cholesterol is the precursor for the synthesis of steroid hormones that are important in controlling physiologic processes such as stress, plasticity, and depression [11]. Fifth, the cholesterol biosynthetic pathway generates molecules (isoprenenyl-pyrophosphate, geranyl-pyrophosphate, farnesyl-pyrophosphate) used for the modification of proteins and RNA and for the biosynthesis of ubiquinone, dolichol and Heme A [65, 66,196]. Modification of G-proteins is critical for their function. Thus cholesterol biosynthesis may indirectly influence receptor mediated physiologic processes controlled by G-protein coupled receptors. Finally, the cholesterol composition affects the activity of transmembrane proteins and receptors. For example, gamma amino butyric acid (GABA) transport requires cholesterol and lipid rafts/coated pits that are implicated in endocytosis and protein remodeling are all eriched with cholesterol [138,193,200,209,227]. These functions of cholesterol underscore its importance in brain function. For example, 24S-hydroxycholesterol, the major excretion product and has been shown to increase in CSF of AD subjects [24,60]. Moreover, CYP enzymes that oxidize cholesterol are differentially expressed in brain cells and around amyloid plaques in the AD brain [33]. Several other brain diseases are associated with metabolism, transport, recycling, excretion and degradation of cholesterol [2,24,64,120,135, $143,161,163,178,202,227]$.

Levels of cholesterol in the brain are controlled by the rate of biosynthesis, catabolism, transport and excretion. Two major pathways for cholesterol biosynthesis are known in mammals (Fig. 4). Both pathways require acetyl-CoA derived from glucose oxidation or from fatty acid metabolism (Fig. 4) [85,87,112, 113]. Conversion of HMG-CoA to mevolonic acid by HMG-CoA reductase is the rate-limiting step for both pathways in many cells including glial cells. In one pathway, 7-dehydrocholesterol is an intermediate while the alternate route involves 7-dehydrodesmosterol as an intermediate (Fig. 4). Several enzymes involved in cholesterol synthesis have been characterized in various brain cells. The differential expression of these enzymes in brain cells suggests that there is transcellular metabolism or highly specialized functions of cholesterol products by brain cells or specific brain regions. For example, astrocytes synthesize two to three times more cholesterol than neurons and fibroblasts [169]. Oligodendrocytes that are normally involved in myelination have higher capacity to synthesize cholesterol, underscoring the need and importance of cholesterol for myelination [212].

Cholesterol synthesis and distribution may play a critical role in the onset and progression of degenerative brain disorders. A study showing that cholesterol synthesis is higher in developing neurons but is decreased with aging has several implications for aging and neurodegenerative diseases [227]. While total cholesterol may not change, the distribution of choles- 


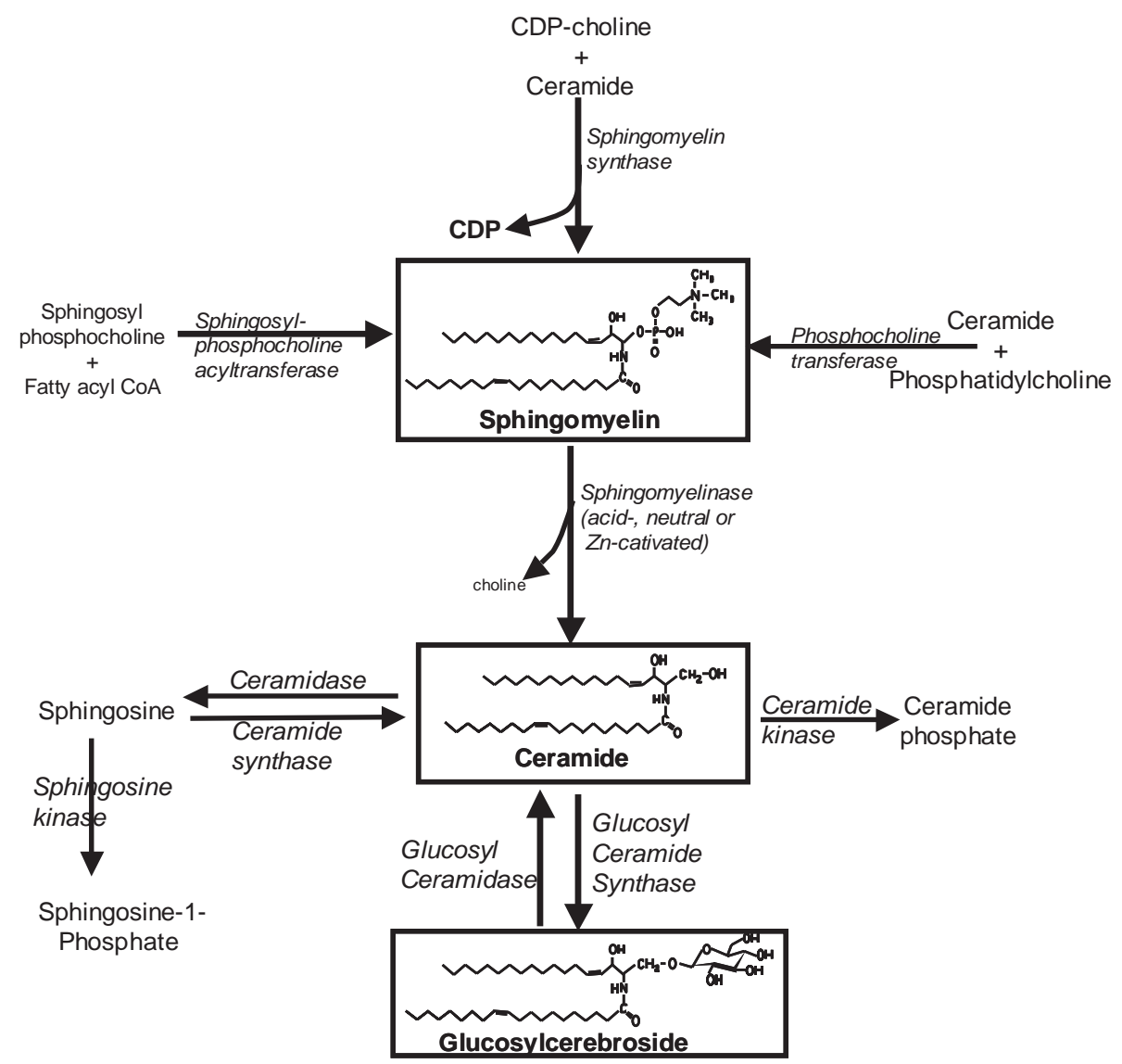

Fig. 3. Metabolism of sphingomyelin and ceramide.

terol favors amyloid peptide accumulation upon aging. In terms of biomarker discovery, it may be important to examine the biosynthetic pathway in individuals with a neurodegenerative disease to determine whether cholesterol biosynthesis is slower than in normal subjects. Alternatively, a compromised BBB may disrupt the tight control of brain cholesterol levels. Finally, enhanced catabolism via CYP-dependent mechanisms or by auto-oxidation may generate oxidative products that cross the BBB easily and are excreted from the brain. Any decrease in cholesterol level may result in enhanced proteolytic digestion of membrane bound proteins by exposing them to proteases or secretases in the case of amyloidosis (AD) [27,60]. Other ramifications may include enhanced oxidation or increased inflammation, leading to neuronal cell death.

Since cholesterol is independently controlled in the brain, it is unlikely to be strongly influenced by inhibitors of biosynthesis if these do not cross the BBB or by dietary manipulation, since the plasma pool is not interchangeable with the brain pool. Given an esti- mated half-life of 5 years in the brain, enhanced degradation or CYP-mediated catabolism of cholesterol will significantly alter its levels [28,33,136,224].

Lipoprotein-mediated uptake and reverse transport is proposed to play a small role in the removal of cholesterol from the brain. However, several groups have characterized many cholesterol-binding proteins in the CSF and brain [2,53,131,217,226]. If not directly involved in cholesterol transport out of the brain, these proteins may be crucial in transporting cholesterol within the brain from sites of synthesis to sites needed for neuronal growth or for the synthesis of neurohormones. There may also be cross-talk between $24 \mathrm{~S}$ hydroxycholesterol and lipoprotein-dependent transport since $24 \mathrm{~S}$-hydroxycholesterol has been shown to enhance ApoA1 dependent efflux of cholesterol from cultured cells. Several lipoproteins synthesized in the brain have been detected in CSF by 2D gels [80]. These include ApoA1, ApoD, ApoJ, and ApoE. Expression of one ApoE allele (ApoE4) increases the risk of late onset AD [32,41,124,127,134,238]. ApoE pro- 


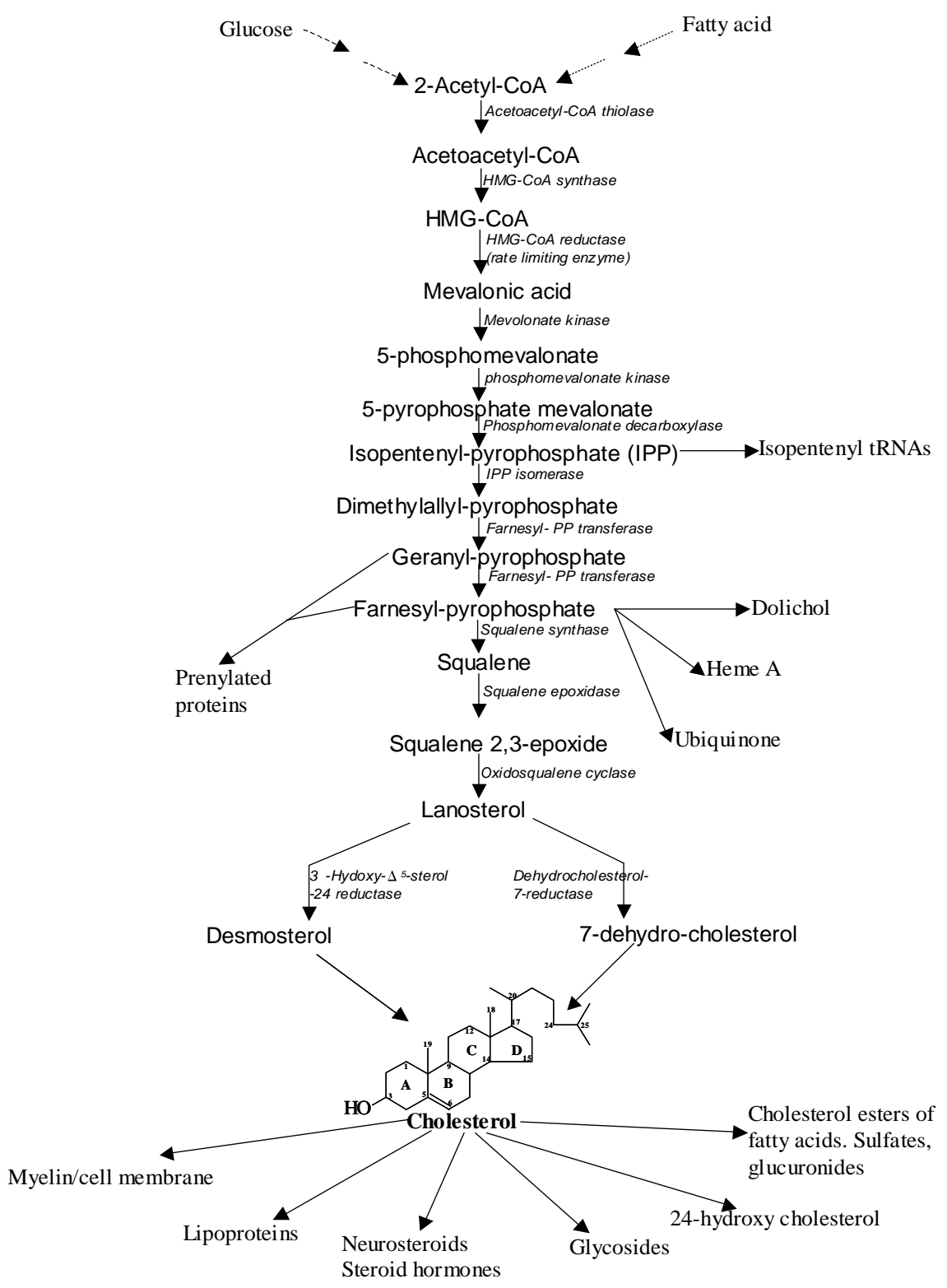

Fig. 4. Metabolism of cholesterol- Cholesterol is synthesized by a multi-enzyme pathway starting with 2 molecules of acetyl-CoA. Hydroxyl-methylglutaryl-CoA reductase is the rate limiting enzyme of this pathway. Several intermediates of cholesterol biosynthesis are substrates for molecules such as dolichol, Heme A and ubiquinone. Some intermediates are also used for post-translational modification of proteins. Once formed in the brain, cholesterol is used for nerve cell growth, for the formation of steroids and glucosides. CYP activity converts cholesterol to hydroxycholesterol that easily crosses the BBB for excretion. Cholesterol is also converted to sulfate or glucuronides dereivatives.

duced in high amounts by astrocytes is important in cholesterol transport in the brain and is a major component of cholesterol-containing lipoproteins found in CSF. In vitro studies show that ApoE3 is more efficient in cholesterol transport and delivery to neurons than ApoE4. In addition, ApoE3 from astrocytes stimulates neuronal outgrowth more than ApoE4 expressing cells [156]. Lipoproteins are integral parts of HDL or
LDL particles that are the suggested route of cholesterol transport from the liver to organs and vise versa. Scavenger receptors (SR-B1) or other lipoprotein receptors may be responsible for cholesterol removal from the brain. LDL receptor (LDLR) is expressed in the brain [17]. Seven members of the LDLR family have been characterized. Typical features of the LDLR include a ligand binding domain, an EGF repeat, a trans- 


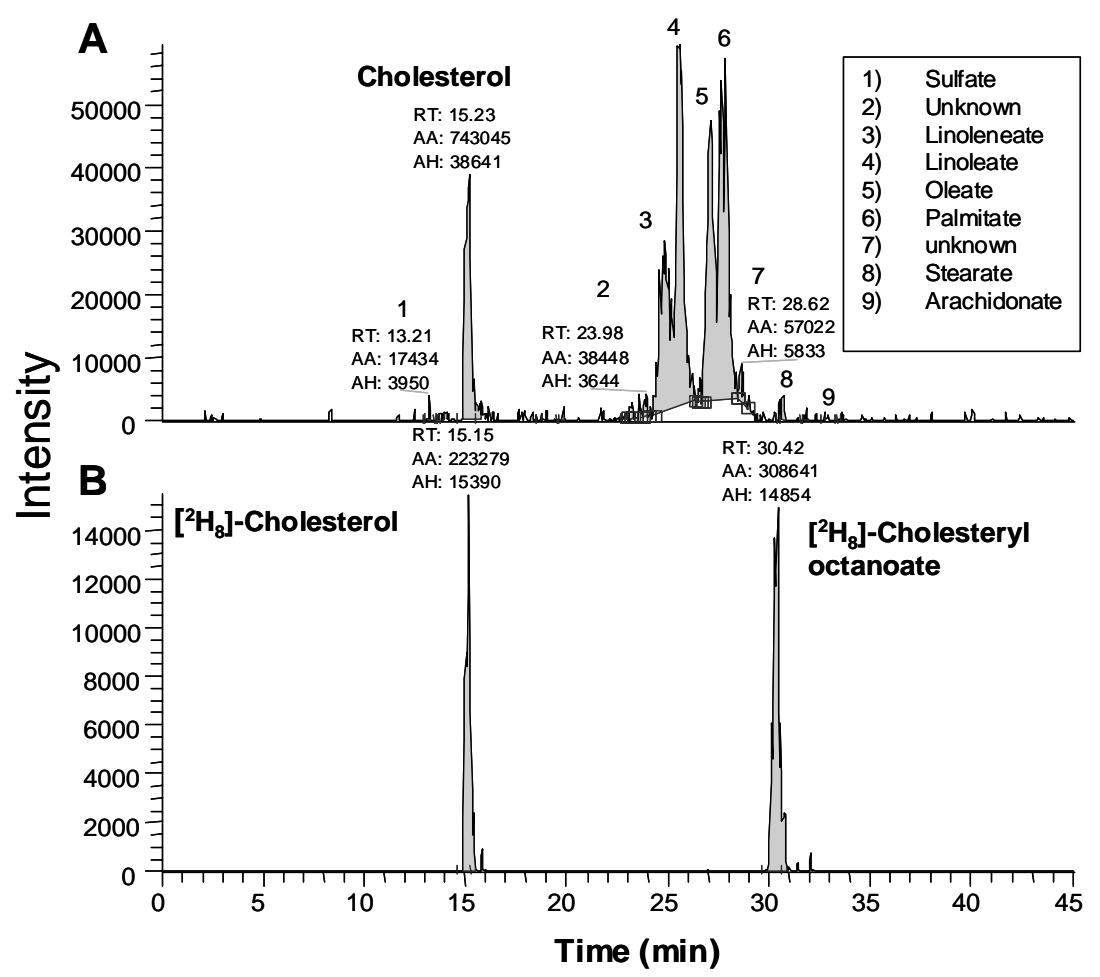

Fig. 5. LC-APCI tandem MS of cholesterol in CSF- Cholesterol and esters in CSF from 79 year old female- Positive ion mass spectra obtained by APCI/MS ${ }^{2}$ for cholesterol and its derivatives in CSF (A) and SRM of internal standards (B). Peaks for cholesterol sulfate, free cholesterol and fatty acid esters of cholesterol are numbered from 1-9 (A). Deuterated internal standards are shown on Fig. 5(B).

membrane segment and a cytosplasmic tail containing a NPXY motif that controls endocytosis and interaction with the phosphotyrosine binding-containing proteins $[17,158,166,185]$. ApoE is a common ligand of the LDLR family. ApoE binds to LDLR and initiates a signaling pathway that promotes cell survival (Akt).

In addition to lipoproteins, several ATP-binding cassette $(\mathrm{ABC})$ transporters assist in the shuttling of cholesterol from glial cells to neurons [217]. Preliminary results from our laboratory combining 2D-LC with a linear ion trap mass spectrometer have revealed several isoforms of ABC proteins in CSF (unpublished data). Studies to determine whether their expression or isoform profiles change in brain diseases or whether their expression is linked to cholesterol are underway in our laboratory.

Cholesterol metabolism is associated with several diseases including neurodegeneration, hypercholesterolemia, AD, multiple sclerosis, and Niemann Pick disease type C. CNS cholesterol is mainly unmodified; it is not conjugated to fatty acids, or modified by sulfates and glucuronides. Our studies show several cholesterol molecular species in CSF including fatty acid esters and sulfates (Fig. 5). CSF may be a medium of trans- port of cholesterol from areas of synthesis to other parts of the brain where it may be needed for hormone synthesis or neuronal growth. Alternatively, cholesterol and its esters may exist in lipoprotein bound particles that are needed for LDLR binding. Studies showing LCAT, cholesterol esters and various constituents of lipoproteins in CSF suggest that this mode of cholesterol transport may be important within the brain for neuronal function. These studies underscore the importance of cholesterol in growth and neurodevelopment. Considerable levels of esterified cholesterol in human CSF may reflect a preferred mode of extracellular transport since most cholesterol within brain cells is free. It remains to be determined whether levels of free or esterified cholesterol are altered in CSF from subjects with neurological diseases compared to normal subjects. Moreover, it would be of interest to determine whether profiles of cholesterol, CYP, lipoproteins, receptors and ATP-binding cassette proteins can form a multiplex biomarker panel for the detection of neurological pathologies linked to cholesterol metabolism in the brain. 


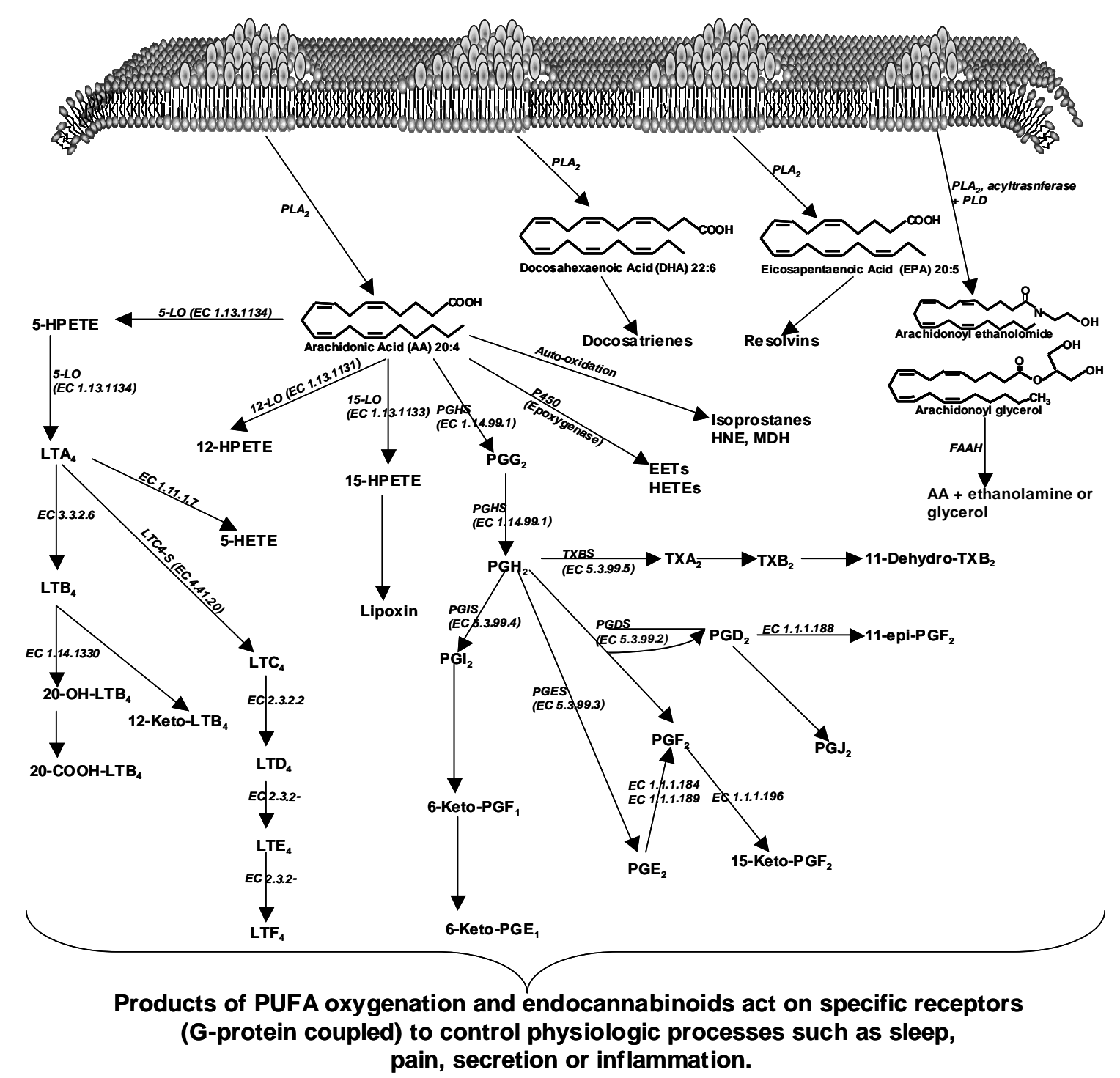

Fig. 6. Oxygenation of PUFAs and endocannabinoid biosynthesis- PUFAs are released from the lipid bilayer by the action of PLA enzymes. Free PUFAs such as AA, DHA or EPA are metabolized by major oxygenases pathways numbered 1-4. 1) Lipoxygenases (5-LO, 12-LO or 15-LO) generate hydroxyperoxyeicosatetraenoic acid (HPETE) that are subsequently converted to leukotrienes (5-LO) or lipoxins (15-LO). 2) PUFAs can also be metabolized via the Prostaglandin $\mathrm{H}$ synthase (PGHS) pathway to form $\mathrm{PGH}_{2}$. Terminal synthases convert $\mathrm{PGH}_{2}$ to prostanoids. PGIS, PGES, PGDS and TXBS are the major terminal synthases responsible for $\mathrm{PGI}_{2}, \mathrm{PGE}_{2}, \mathrm{PGD}_{2}$ and $\mathrm{TXB}_{2}$ biosynthesis. 3) Cytochrome $\mathrm{P} 450$ monooxygenases (P450) convert PUFAs by hydroxylation to hydroxyeicosatetraenoic acids (HETEs), by allylic oxidation to generate isomers of HETEs and by olefin bond epoxidation to generate regioisomers of epoxyeicosatetraenoic acids (EETs). 4) Auto-oxidation of PUFAs can generate isoprostanes or neuroprostanes and oxidized lipid products such as malonaldeylde and 4-hydoxynonenal (HNE). 5) DHA and EPA can serve as substrates of these oxygenases to for docosatrienes and resolvins, respectively. 6) A combination of acyltransferase activity in concert with PLD is proposed for the biosynthesis of the endocannabinoid, arachidonoyl ethanolamide (AEA). AEA levels in the brain may be controlled in part by fatty acid amide hydrolase (FAAH) activity. Overall, products from these pathways are implicated in processes such as sleep, pain, secretion and inflammation.

\subsection{Fatty acids, eicosanoids and endocannabinoids}

Compared to other tissues, the brain is highly enriched with PUFAs. The major classes of PUFAs in the human brain belong to the $n-6$ or $n-3$ classes where $\mathrm{n}$ denotes the total number of carbon atoms and the numbers denote the presence of a double bond 6 or 3 carbon atoms from the terminal omega $(\omega)$ carbon atom. The major PUFA species are arachidonic acid (AA, 20:4, n-6), eicosapentaenoic acid (EPA, 20:5, n- 


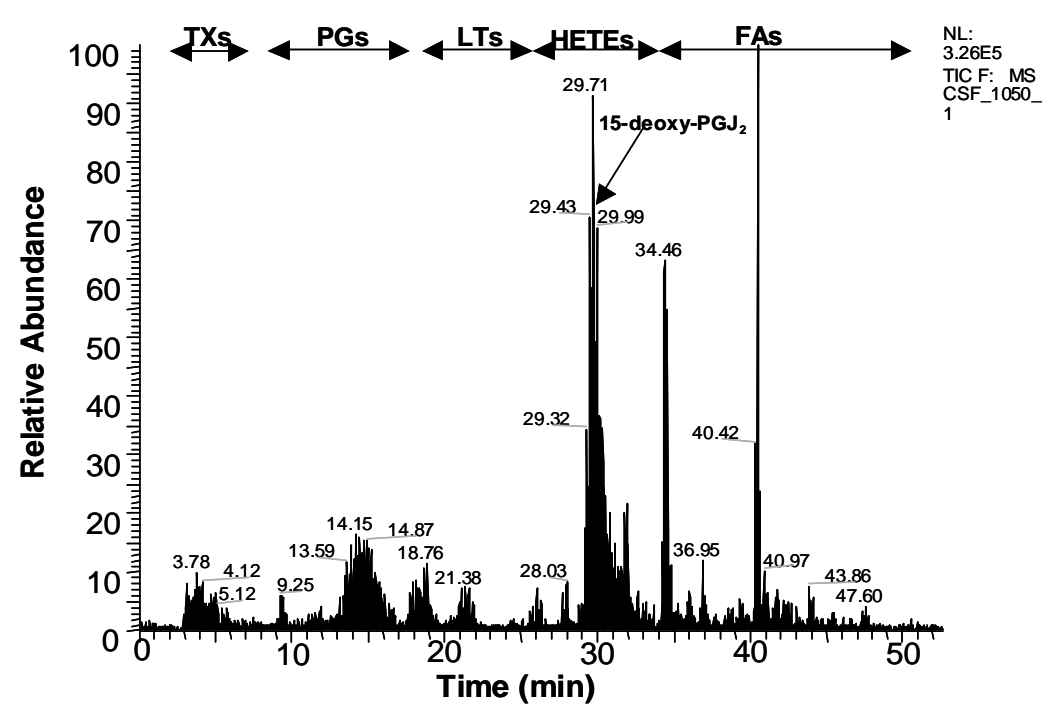

Fig. 7. LC-ESI tandem MS of eicosanoids, isoprostanes and fatty acids in CSF- After the addition of 2 ng deuterated internal standards to $400 \mathrm{ul} \mathrm{CSF}$, eicosanoids and free fatty acids were extracted using ethyl acetate. Samples were reconstituted in water/methanol (70:30) containing $0.01 \%$ acetic acid. LC-negative ion ESI-MS ${ }^{2}$ was performed with SRM of parent and product ions for thromboxanes (TX), prostanoids (PTs), leukotrienes (LT), isoprostanes and fatty acids (PUFAs).

3) and docosahexaenoic acid (DHA, 22:6, n-3) [146]. Mammals cannot synthesize AA, EPA and DHA because they lack the desaturase enzyme required to introduce a double bond at the $n-6$ and n-3 position [125]. Therefore, the major precursors of PUFAs must be provided by the diet and are thus referred to as essential fatty acids (EFAs). Linoleic acid (18:2, n-6) and $\alpha$ linolenic acid (18:3, n-3) are the major plant oil-derived EFAs. EFAs are important in brain development and function [54,125,186,214]. Once ingested, EFAs are subjected to elongation and desaturation to form several PUFAs including AA and DHA [199]. Considerable evidence suggest that PUFAs diffuse through the lipid bilayer and FA transporters have also been implicated in their uptake $[173,176]$. Upon internalization, PUFAs are converted to CoA-derivatives by acylCoA synthetases (ACS), which require ATP. PUFACoAs are utilized for the synthesis of phospholipids, triacylglycerides or can be utilized for energy generation via mitochondrial $\beta$-oxidation $[38,130,145,157]$. PUFA-CoAs also function as signaling molecules [38, 93]. PUFA levels and metabolism have been implicated in several neurological processes. These include neural outgrowth, neurodegeneration, depression, membrane activity of receptors and the sodium pump, synaptic lipid signaling and plasticity $[29,86,115,140,142,194$, 214,232]. Although PUFAs are thought to be involved in diseases ranging from $\mathrm{AD}, \mathrm{PD}$, stroke, and anxiety, the mechanisms that would account for their roles still awaits discovery $[115,140]$. PUFA levels may be influenced by uptake from the diet, biosynthesis and release/catabolism within the brain.

Phospholipases release PUFAs from membrane phospholipids. Released PUFAs are converted to bioactive lipids or other signaling molecules (Fig. 6). Bazan has recently reviewed the significance of PUFAs in synaptic lipid signaling [14]. Likewise, the importance of phospholipases in releasing PUFAs from phospholipids and their potential role in brain function has been reviewed [73]. However, the isoforms of phospholipases and the source and mechanism by which PUFAs may be mobilized for eicosanoid formation are not yet defined in CSF. Given the presence of several oxygenases and terminal synthases that can convert PUFAs into eicosanoids, resolvins and docosanoids/neuroprostanes [139,186] (Fig. 6), it is important to determine the PUFA composition of brain lipids and the ancillary pathways that control their availability to neurons. Using LC-negative ion ESI tandem MS, we have detected many eicosanoids, isoprostanes and fatty acids in human CSF (Fig. 7). Changes in the amounts of these molecules in CSF may not only be an indication of physiologic process in the brain, but could suggest pathologic conditions.

In addition to eicosanoids, another AA-derived class of molecules implicated in pain reduction, motor regulation, learning, memory, reward and appetite has been recently described $[57,100,215]$. These molecules are 


\section{A}

RT: $0.00-68.16$

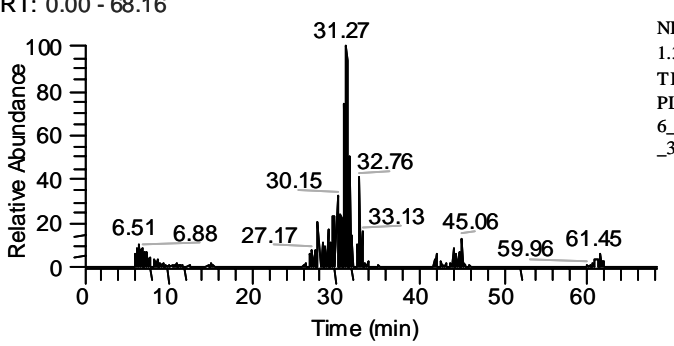

C

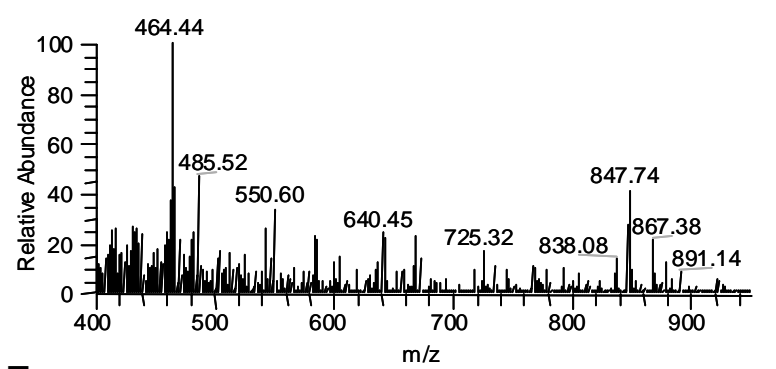

E

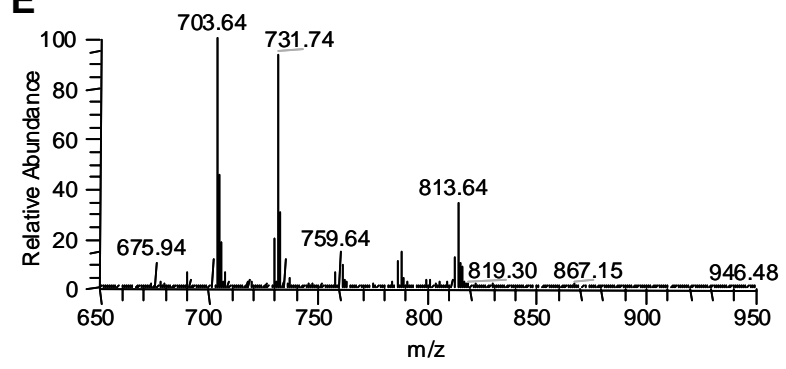

B

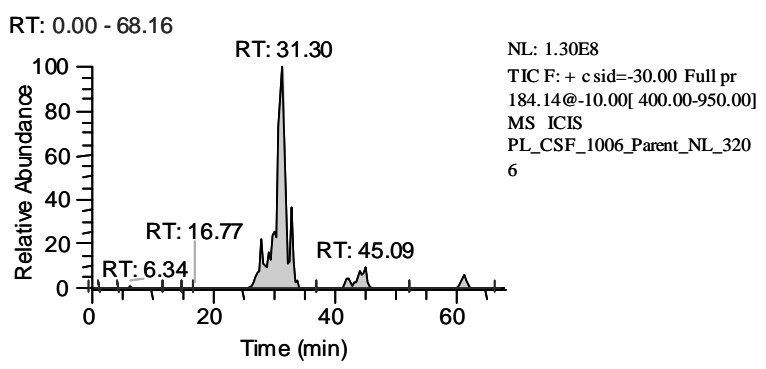

D

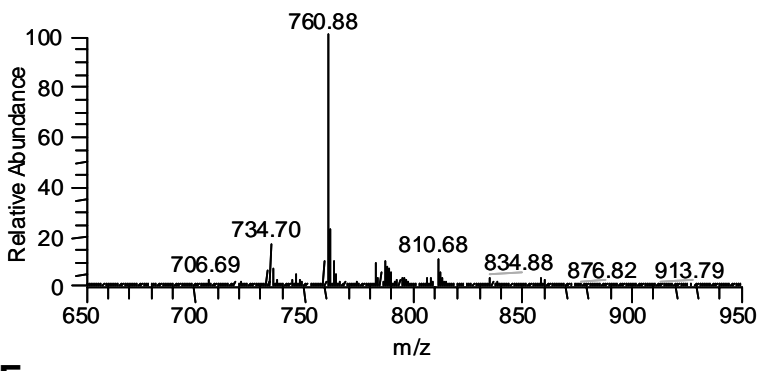

$F$

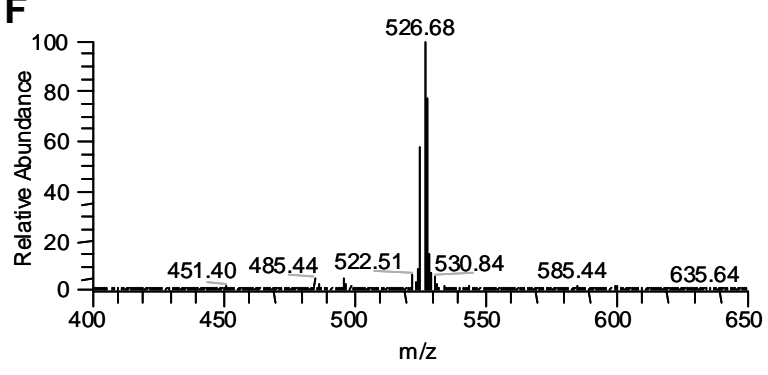

Fig. 8. LC-ESI tandem MS of phospholipids in human CSF- $10 \mathrm{ng}$ phospholipids standards were added to $200 \mu \mathrm{l}$ CSF and total lipids were extracted using chloroform and methanol. Samples were reconstituted in chloroform/methanol (2:1) and LC-positive ion ESI-MS was performed with parent ion monitoring for choline containing phospholipids or neutral ion loss for PE, PI, PG and PS. Figure 8(A) shows the TIC obtained for all phospholipids classes while Fig. 8(B) shows a chromatograph of choline-containing molecular species. Figure 8(C) shows spectra of sphingosylphosphocholine/phosphocholine species eluting at 1-20 min, PC at 20-35 min (Fig. 8D), sphingomyelin at 35-45 min (Fig. 8E) and lysophosphatidylcholine/PAF at 45-65 min (Fig. 8F). Over 450 choline-containing molecular species are identified in CSF.

known as endogenous cannabinoid ligands or endocannabinoids. The first endocannabinoid was initially identified as an ethanol amide derivative of AA and termed arachidonamide or anandamide (Fig. 6). A second endocannabinoid also contains AA that is attached to glycerol (2-arachidonoyl glyceryl ester or $2 \mathrm{AG}$ ). Endocannabinoids are synthesized and released from neurons upon stimulation [215]. Inactivation of anandamide and 2-AG is accomplished by rapid uptake via a membrane transporter (AMT) followed by intracellular enzymatic degradation by fatty acid amide hydrolase (FAAH) [100,215]. Endocannabinoids bind to the $\mathrm{CB} 1$ receptor. Similar to the CB1 receptor, the distribution of AMT and FAAH are high in the hippocampus, cerebellum and cerebral cortex. Recent studies have clarified endocannabinoid signaling. Upon release by postsynaptic neurons, endocannabinoids diffuse back to the presynapatic neurons where they act on CB1 receptors to inhibit release of neurotransmitters such as GABA and glutamate [3]. Interestingly, recent studies show that $\mathrm{CB} 1$ receptors are coupled to another lipid second messenger, ceramide [3]. Also a proposed pathway for endocannabinoid-induced apoptosis involves ceramide. Structural similarities between 2AG and lysophosphatidic acid (LPA) also suggest possible cross-talk between these lipid-signaling ligands and their receptors. Measurement of these signaling molecules in CSF and correlation of any changes in their levels with enzyme activity or protein levels will represent disease markers and provide tangible path- 
ways that can be influenced by therapy.

\section{Methods for measuring lipids in CSF}

Early methods for analyzing the lipidome depended on organic extraction coupled with thin layer chromatography (TLC) or high performance liquid chromatography (HPLC). Further structural identification of lipid classes and molecular species were possible only after extensive digestion of lipids, derivatization and further chromatography (Table 2). This laborious strategy employed over many decades revealed several metabolic pathways. However, low sensitivity and the labor-intensive process limited extensive profiling of lipid molecular species. Advances in mass spectrometry have made it possible to detect thousands of lipid molecular species. Initial advances in lipid analyses were made by Murphy and colleagues using fast atomic bombardment [44,117]. The advent of soft ionization processes such as ESI-MS ${ }^{2}[108,171,175]$ or APCI-MS ${ }^{2}$ [35] have revolutionized metabolic profiling of lipids. Not only are these modern instruments sensitive, but enzyme digestion and derivatization procedures are not needed for most lipids. By combining LC with MS, many more molecular species of lipids can be measured. For example, Fig. 8(A) shows the total ion current (TIC) obtained from CSF phospholipids monitored using LC tandem MS with parent ion monitoring of $\mathrm{PC}$ or neutral ion loss for PE, PI, PS and PhosGl. Figure 8(B) shows the TIC of choline-containing phospholipids species. Spectra of choline-containing molecular species corresponding to sphingosylphosphocholine/phosphocholine, PC, sphingomyelin and PAF/LPC are shown in Figs $8(\mathrm{C})$, 8(D), 8(E) and 8(F), respectively. Over 450 different molecular species were identified in human CSF. Similar to PC, hundreds of PE, PI, PS and PhosGl molecular species were identified in CSF (data not shown). Other studies use 2D mass spectrometry with either parent ion monitoring, neutral ion loss of specific lipid fragments or multiple reaction monitoring (MRM) to identify hundreds of lipid species [102,207] (Table 2). Information from these studies is important in obtaining structure, composition of lipids in cells, turnover of lipids and characterization of lipid synthesis/transport and degradation pathways.

\section{Proteomic strategies for the identification of lipid-metabolizing proteins in CSF}

While lipidomic approaches reveal lipid composition, protein expression and the putative biosynthetic pathways in CSF that account for specific changes in lipid levels or distribution can best be understood if the levels and activity of metabolizing enzymes and transport proteins are determined. For example, if the level of PAF is found to change in CSF for a specific disease, various possibilities may account for this change. An increase in $\mathrm{PLA}_{2}$ activity resulting in the generation of lysophosphatidylcholine (LPC) and subsequent acetylation of LPC by acetyltransferase can result in an increase in PAF. Likewise, a decrease in PAF acetylhydrolase activity may result in a build up in PAF levels. Alternatively, an increase in PAF acetylhydrolase activity will decrease PAF levels. Similar arguments can be applied to most lipid signaling molecules (eicosanoids, $\mathrm{DAG}, \mathrm{IP}_{3}$ etc). One way of understanding why there is a change in the lipidome is to examine all the proteins in the biosynthetic and catabolic pathways associated with specific lipid molecules as outlined on Fig. 9. In addition to the use of systematic animal knockout models, enzyme analyses or use of proteins chips, 2D gel electrophoresis and shotgun sequencing of CSF proteins are the most valuable approaches for interrogating changes in lipid-metabolizing proteins. In 2D gel electrophoresis, CSF proteins are identified by their isolelectric point (pI) and by their size. A 2D map is then obtained by staining gels with fluorescent dyes or with silver stains [92,101]. Densitometric profiles and normalized total densities are obtained for relative quantification. Proteins on 2D gels are identified by extraction and MS sequencing, immunoblotting, or by reference to published 2D database (SWISS-2DPAGE, http://www.expasy.org/ch2d/). While very laborious, $2 \mathrm{D}$ gels are useful because they resolve posttranslationally modified isoforms of proteins [101].

In shotgun sequencing, CSF proteins are reduced, denatured and alkylated prior to enzyme digestion, often with trypsin. Peptide fragments are subsequently resolved using capillary columns and detected using an ion trap mass spectrometer. Sequences are obtained using several software packages such as Sequest/Bioworks and multidimensional protein identification technology [225]. Improvements in mass spectrometric methods and the availability of human sequence databases makes it possible to analyze complex mixtures of peptides in CSF by liquid chromatography coupled to tandem mass spectrometry. The handling of 


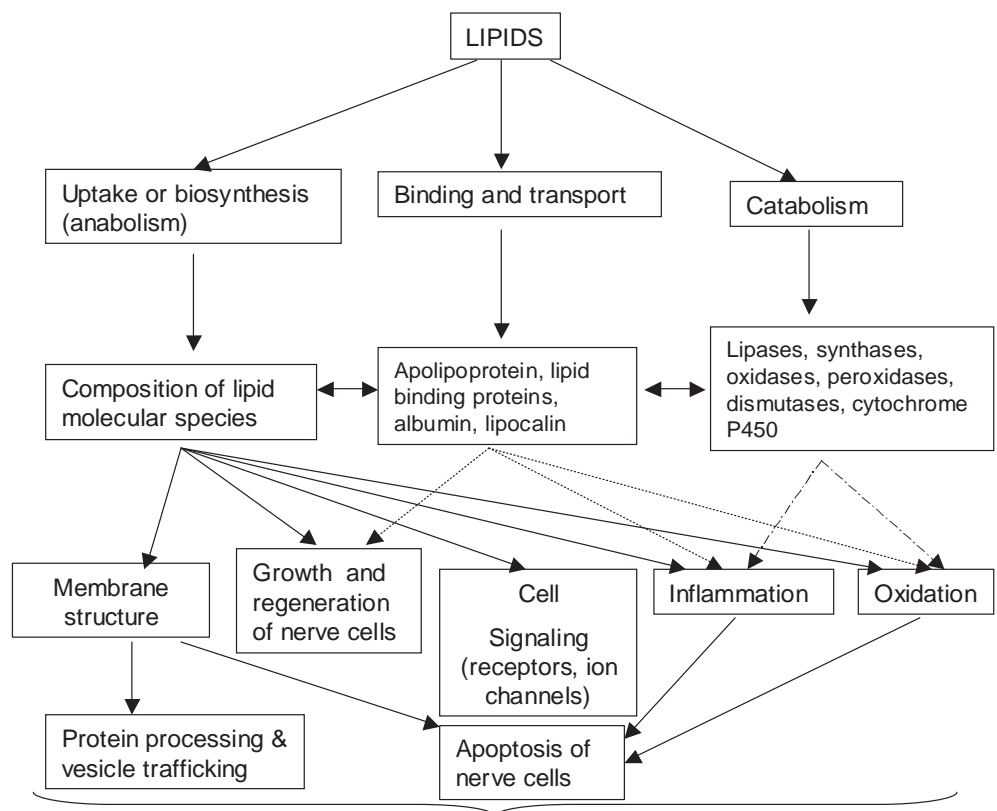

Pathophysiological changes in the brain characteristic of specific diseases.

Fig. 9. An overview of lipid metabolism and its pathological significance- A comprehensive analysis of CSF lipids composition by LC tandem MS will reveal how lipids get into the brain, their usage once in the brain and physiologic processes that they influence. Lipid compositional data are complemented by measures of proteins that metabolize lipids in the CSF. This approach will result in a better understanding of the pathophysiology of brain diseases.

data using automated data processing with improved algorithms has increased confidence in the identification of proteins $[42,63]$.

Once both the identities and the levels of CSF proteins have been determined, apparent differences in the proteomes of normal and diseased individuals can be used to explain the mechanisms by which changes in the lipidome occur in disease. Mechanistic changes could be reflected in observed differences in protein abundance (COX, 5-LO, $\mathrm{PLA}_{2}$, etc.), or variance in the levels of protein activation (e.g., phosphorylation of $\mathrm{CPLA}_{2}$ ). This combinatorial strategy will be useful in assessing confidence for novel lipid or protein biomarkers and allow for direct comparison between variable levels attributable to chance, diet, genetic variability and environment and changes related to the onset and progression of disease. Furthermore, this strategy will prove to be clinically useful in helping to develop intervention strategies involving drug inhibitor discovery as well as in the rational design of diet/lifestyle changes necessary for disease prevention.

\subsection{Some examples of lipid metabolizing proteins of interest in $\mathrm{CSF}$}

Several 2D gel electrophoresis studies have revealed lipid-metabolizing proteins in human CSF. These pro- teins may be classified by their functions in biosynthesis, transport or catabolism/degradation of lipids. Our studies show nine different prostaglandin D synthase (PGDS) isoforms, 4 apolipoprotein (ApoA1) isoforms, and 9 apoliprotein $\mathbf{J}$ (Apo $\mathbf{J}$ ) isoforms in CSF [80]. These initial studies are being expanded using 2Dcapillary LC in combination with high resolution, high sensitivity linear ion trap mass spectrometry. With this approach, we have been able to increase the dynamic range more than 7 fold such that less abundant proteins not visualized on 2D gels are discovered with high statistical confidence [104].

Lipid metabolizing proteins that we have found in CSF include enzymes with a variety of functions such as: ligases, synthases, transferases, lipid binding proteins, ABC cassette proteins, all major lipoprotein isoforms, lipases, COX, LO, CYP450 enzymes, kinases for choline, ethanolamine, inositol and PI, and receptors for steroids and prostaglandins (unpublished data). Bazan and colleagues, and others have extensively reviewed roles of COX in brain physiology $[13,16]$. Other studies have shown close association of $\mathrm{cPLA}_{2}$ to amyloid plaques in $\mathrm{AD}$ brain and the importance of phospholipases in the brain has been reviewed [47, $70,72,73,201]$. The importance of apolipoproteins in lipid transport in the brain has been suggested based on 
Table 2

Methods for profiling lipids classes

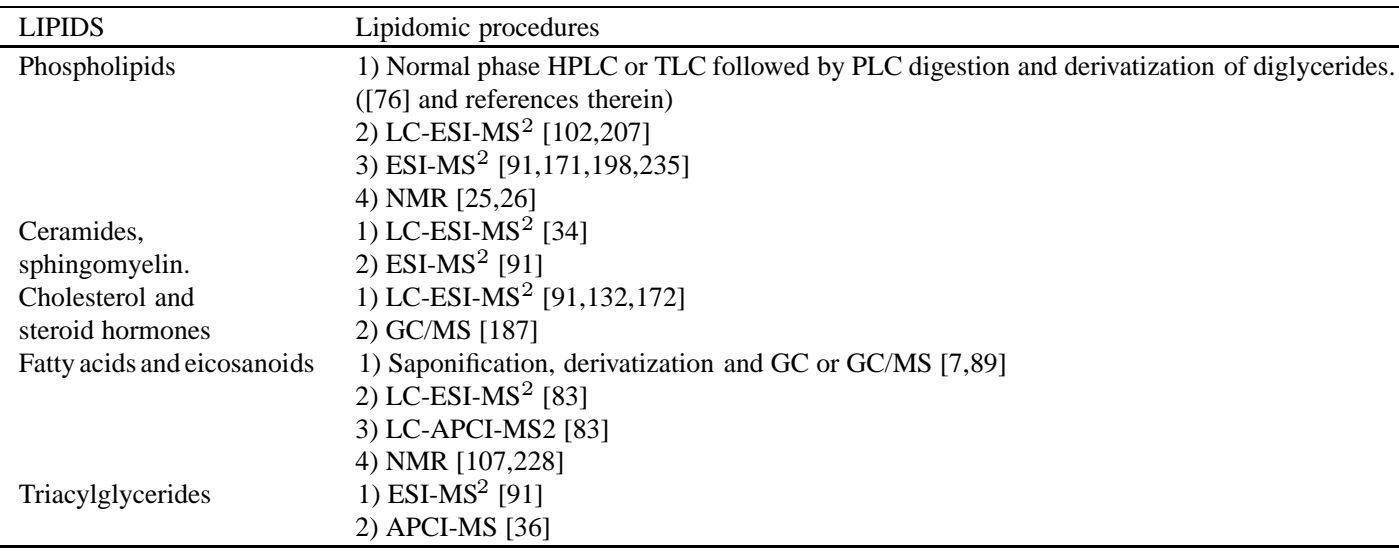

cell studies showing increased secretion of ApoE and cholesterol by astrocytes over-expressing ApoE [156]. Close association of ApoE4 alleles to late onset AD and epidemiological studies showing a link between high cholesterol to $\mathrm{AD}$ has given more credence to a link between ApoE and cholesterol transport [137,150, 156]. However, the functions of other CSF lipoproteins are not known. Given that ApoA1 interacts with the ABC cassette transporter and ATP phospholipid binding proteins to transport cholesterol in cells [223, 237], it is likely that a similar mechanism takes place in the brain. While of great importance to brain lipid metabolism, these can not be fully addressed because of the limited knowledge in the living brain. We will concentrate on our discovery of groups of enzymes that exemplify synthesis and degradation of bioactive lipid molecules. Specifically, we will review platelet activating factor acetylhydrolase and CYP enzyme isoforms that are important in cholesterol, neurosteroids and PUFA metabolism.

\subsection{Platelet-activating factor acetylhydrolase (PAFA)}

At the site of inflammation, several cells are recruited to counteract tissue damage. Cells are recruited to these sites by mediators such as platelet-activating factor (PAF). PAF is a phospholipid that is a potent mediator of inflammation. PAF is formed by sequential action of $\mathrm{PLA}_{2}$ on PC to generate LPC that is subsequently acetylated at the $s n-2$ position by acetyltransferase. PAF-like molecules can also be formed by oxidative fragmentation of PUFAs at the $s n-2$ position of PC $[46,77,97]$. PAF receptor antagonists, thromboxane $\mathrm{B}_{2}\left(\mathrm{TxB}_{2}\right)$ and leukotrienes $\mathrm{C}_{4}\left(\mathrm{LTC}_{4}\right)$ reduce PAF activity [69]. The biological properties of PAF are diminished by hydrolysis of the acetyl moiety or the short-chain oxidized esters.

PAFA hydrolysis of the $s n-2$ ester bond of plateletactivating factor (PAF) and PAF-like oxidized phospholipid species release an acetate or oxidized moiety and lysophosphatidylcholine, thus attenuating the bioactivity of PAF by reducing its levels. Several PAFA isoforms ( 1 secreted and 4 intracellular) have been cloned or characterized based on substrate specificity, cellular localization and structure. Isoform $1 \mathrm{~b}$ forms a Gprotein-like complex consisting of two catalytic subunits (a1 and a2) and a regulatory subunit (b). Another well-characterized isoform of PAFA consists of a single polypeptide and is homologous to plasma PAFA. Isoform II has anti-oxidant properties and a catalytic triad of amino acids characteristic of most esterases, including the $\mathrm{G}$ motif found in most serine esterases and lipases $[4,114]$.

Deficiency in plasma PAFA is associated with stroke, asthma, myocardial infarction, brain hemorrhage and non-familial cardiomyopathy $[4,114]$. Animal studies and preclinical studies show that recombinant plasma PAFA can prevent inflammation and thus has the potential of controlling human inflammatory diseases [211, 222]. As much as two thirds of PAFA activity is associated with LDL and the remainder is found in HDL particles. Expression of PAFA is regulated by bacterial liposacharides (LPS), cytokines, PAF and the lyso-PAF concentration. PAFA levels are strongly correlated to LDL cholesterol and an increase in PAFA has been shown in essential hypertension, vascular disease, ischemic stroke, diabetes mellitus, rheumatoid and nonrheumatoid arthritis $[8,159,211,231]$. In other diseases such as asthma, Crohn's disease, sepsis, acute myocardial infarction, multiple organ failure, juvenile rheuma- 
toid arthritis and systemic lupus erythematosis, PAFA has been shown to decrease. Given the proposed role of PAF in plasticity and the role of inflammation in brain diseases, PAFA levels may change with diseases and control of PAFA activity may influence neurological pathologies.

\subsection{CYP450 and brain function}

Cytochrome P450 (CYP) are phase 1 enzymes involved in oxidative activation /deactivation of compounds or toxins [233]. CYPs belong to four major families (CYP1, CYP2, CYP3 and CYP4) that are further subdivided into subfamily members. The liver is a very rich source of CYP [233]. However, whole brain CYP activity is approximately $1 \%$ activity of the liver. Specific brain regions or cell types may have higher expression of CYP than others. For example, the major CYP families are localized at the BBB, choroid plexus and posterior pituitary $[148,168,197,233]$. CYP1 family proteins are often expressed in basal ganglia and cerebellum of human brain. CYP2, especially the D6 subfamily has been mapped to the BBB of human brain, are expressed mainly in arachnoid, choroid plexus and vascular areas as well as in neuronal cells. CYP3 family enzymes are mainly localized in pituitary cells and are probably involved in the regulation of growth hormone.

Higher levels of CYP are associated with oxidative stress. Drugs, xenobiotics and endogenous compounds are known to be substrates of CYP. Endogenous substrates include neurotransmitters such as dopamine, neurosteroids and PUFAs. PUFAs are modified by CYP1A, 2A, 2C, 2D, 2E, 2J and 4A [23,103,131]. Arachidonic acid is converted to epoxygenase metabolites $(14,15,11,12,8,9,5,6$-epoxyeicosatetraenoic acid, EETs) or $\omega$-terminal hydroxylase metabolites (20, 19, 18, 17, 16 hydroxyeicosatetraenoic acids, HETES) and lipoxygenase-like metabolites (15-, 12-, 9-, 8-, 5 HETES) $[45,131,234]$. In the brain, EETs are produced by astrocytes close to cerebral microvesicles and are likely involved in control of cerebral blood flow. The pituitary and hypothalamus both produce HETEs that stimulate neuropeptide formation. HETEs are also potent vasoactive agents that modulate normal brain function and are altered in cerebrovascular pathologies.

CYPs are also involved in cholesterol and steroid biosynthesis. Steroid hormones influence brain growth and development [131,144,182,191]. Steroids produced by the adrenal glands and the gonads readily cross the BBB. In addition to steroids synthesized outside the CNS, the brain is the site of synthesis of sev- eral neurosteroids that are known to influence its function. Steroids are implicated in behavior, mental illness, activation of the immune system, fatigue, depression, some forms of epilepsy and dementia [131]. The role of CYP family enzymes in PUFA metabolism, steroid biosynthesis and neurotransmitter modification underlines their importance in brain function.

\section{Lipid-related mechanisms in neurological diseases}

The brain is composed of cells (neurons, astrocytes, glial cells, oligodendrocytes, etc) that communicate via chemical or electrical signals in response to stimulation. These cells are highly shielded to prevent fluctuations in ion or chemical concentrations and are separated from the rest of the body by a blood brain barrier. The cell membranes of cells are critical in maintaining ion and chemical balance in the brain. Therefore, drastic changes in lipid composition may have significant pathological ramifications (Fig. 9).

\subsection{Structure and distribution}

Cell membranes are composed of complex lipids (diacyl glycerophospholipids, sphingomyelin, ether phospholipids, plasmalogens and cholesterol) and contain ion channels as well as several receptors for neurotransmitters, neuropeptides or neurohormones. The complexity of lipids is reflected in important ways. First, lipids are composed of different classes and subclasses (e.g., PC, PE and plasmalogen). Second, each class is further differentiated by the fatty acid content that make up thousands of molecular species. Third, some complex lipids such as glycerophosphatidylinositols are modified by phosphorylation of the inositol base at the 3,4 or 5 position to generate PIP, $\mathrm{PIP}_{2}$ or $\mathrm{PIP}_{3}$ derivatives. Fourth, complex lipids are asymmetrically distributed within cell membranes and lipid composition varies within organelles of the same cell. For example, lipid rafts have been shown to be rich in PI-anchored proteins and cholesterol while PUFAs seem to initially accumulate in the nuclear membrane before being remodeled to organelles [155,227]. Fifth, the difference in distribution is not limited to specific cells but also to specific regions of the brain. Sixth, these complex lipids are subject to constant remodeling of fatty acyl groups and are rapidly degraded by phospholipases $\left(\mathrm{A}_{2}, \mathrm{C}\right.$ or $\left.\mathrm{D}\right)$ to generate several lipid derivatives [14]. This complexity coupled with the fact 
that lipids interact with the internal and external environment of cells makes it critical that their composition be well controlled. An abnormal lipid composition or distribution within the cell bilayer is likely to influence important physiologic processes associated with ion channels or receptor function. Several brain diseases described in this review display changes in these physiologic processes.

\subsection{Lipids and secretion}

In response to stimulation, some cells secret neurotransmitters, hormones and enzymes to the extracellular space by a regulated process involving the fusion of cytoplasmic organelles to the plasma membrane. Under other conditions, there is a transfer of organelle membrane components to the cell membrane. The former process involving release of contents has recently been termed secretory exocytosis and the latter involving fusion to cell membrane is known as non-secretory exocytosis[43]. Fusion of organelles to plasma membrane may be important in the transfer of membrane proteins to the cell surface or transfer of specific lipid domains to the plasma membrane. Once transferred to the plasma membrane, these proteins serve as either receptors, transporter of ions and metabolites, or are enzymes generating signals that regulate cell growth and function $[43,52,55,58,59,74,111]$.

Other particles variously called endosomes, vesicles or exosomes are also secreted into the extracellular space without releasing their contents [43]. These particles have been characterized in brain where they may be important in transporting metabolites, hormones or enzymes $[56,75]$. Lipid-rich particles conjugated with various proteins such as HDL and LDL are important in the transport of cholesterol and other lipids between cells and organs. A common feature of these particles, vesicles or exosomes is the involvement of lipids or lipid signaling molecules that are essential components of the particles or are signals that control the secretory process.

An important component in the secretory cascade is the involvement of proteins that generate specific phospholipid moieties needed for secretion. The major proteins involved in synaptic vesicle formation bind major lipids or have activities that modify the phospholipidome. Several classes of proteins known to play important roles in secretion have been characterized. PI kinases generate polyphosphoinositol moieties while lipases form several signaling molecules (Table 1). For example, PIP2 is formed from PI by the action of PI ki- nases. PIP2 has been shown to be required for synaptic vesicle formation [59]. Another example involves the signaling protein, phospholipase D1 (PLD1) that has been shown to control the secretion of tissue plasminogen activator and thus to facilitate neural outgrowth by generating PA [147]. PA can be further metabolized to lysophosphatidic acid by PLA 2 or to DAG by PLC [51, 236]. PA facilitates membrane fusion events and serves as an anchor for membrane proteins. Likewise, several PI species are important in membrane fusion and in the anchor of membrane bound proteins. Lipidmetabolizing enzymes also initiate signaling cascades within cells by forming co-activators of kinases such as PKC or PKA. Activation of PKC by DAG and the release of intracellular calcium mediated by inositol phosphates are events closely associated with secretion. During secretion, cells have to synthesize, and transport lipids to the plasma membrane. The major substrates of phospholipases are the phospholipid components of plasma membranes that are constantly remodeled by the action of lipases and acyltransferases [5,78,82,84]. The activities of all these enzymes replenish lipid components or aid in the transfer of the correct components to specific domains on cell membranes during the cytosis cascade.

\subsection{Lipids, ion channels and receptors}

In addition to anchoring membrane bound proteins, lipids are required for the functions of ion channels, ion pumps and receptors for several neurotransmitters [71]. Lipids not only provide the proper environment for the assembly of ion channel complexes and the barrier that maintains an ion gradient across the cell membrane, but they are also modulators of these same complexes. For example, AA has been shown to regulate the $\mathrm{Na}$ channel and DHA is required for the action of the $\mathrm{Na}^{+}$ pump [29,118,164]. $\mathrm{IP}_{3}$ and related molecules are involved in intracellular calcium mobilization. Byproducts of lipids such as eicosanoids induce signaling processes that eventually influence ion channels and ion pumps. Together, these data underscore the role of lipids and proteins that metabolize lipids in regulating important functions of the brain. The proteins that regulate lipid metabolism or the lipid products that they generate may be altered in various pathological conditions and may be useful indicators or biomarkers of diseases. A recent example is temporal lobe epilepsy (TLE), a common form of epilepsy affecting 1-2\% of the population where expression of PLD1 has been implicated in tissue plasminogen activator release and neurite outgrowth [119,236]. 


\subsection{Signaling molecules, mediators of inflammation and oxidation damage}

Phospholipases and kinases generate several signaling molecules described above. In addition, several oxidized lipids are important in the pathophysiology of brain diseases [14,15,80-82]. Lipids are modified by specific enzymes or by non-specific auto-oxidative processes (Fig. 6). For example, stimulated brain cells release PUFAs such as AA, DHA or EPA that can be converted to eicosanoids or docosanoids by the action of enzymes (COX, LO) [9,14]. Under conditions of oxidative stress, PUFAs are oxidized by reactive oxygen species (ROS) alone or in combination with enzymes to form bioactive signaling molecules known as isoprostanes [30,141,151,154,162,189]. Free PUFA and the concentrations of several oxidized products are known to increase in the brain of AD subjects or subjects with ischemic stroke and PUFA supplementation is neuroprotective $[19,109,115]$. Phospholipids in lipid bilayers are also subject to enzymes and autooxidation. LDL-associated phospholipids are more readily oxidized to form lipids that induce inflammation or can induce apoptosis of cells. Several hydroxylatedderivatives of cholesterol are also formed by specific CYP450 enzymes [131,144]. These hydroxylated or oxidized derivatives of lipids are implicated in neurodegenerative diseases, making it important for the development of sensitive and specific methods to measure products.

Improvements in ionization technology, especially soft ionization methods typified by ESI or APCI have facilitated study of an expanding area of lipidomics dealing with oxidized products (Table 2). This exciting area of research is likely to reveal oxidized lipids that could be biomarkers of biochemical processes (inflammation, immune response, infection, environmental toxicity, etc.) in the CNS. For example, our preliminary studies show a significant increase in oxidized lipid derived products in urine from probable AD (pAD) and PD subjects compared to individuals with no classifiable neurologic disease (N) (Fig. 10). These data were obtained using the less specific thiobarbituric acid (TBAR) assay. Thus, it is not known whether these excreted products are brain-derived or represent a more systemic increase in oxidative stress. Furthermore, the mechanism by which these oxidized lipid products are formed and excreted is not understood.

We have also used negative ion LC-ESI tandem MS with SRM to examine 40-75 oxidized lipid products (thromboxanes, prostaglandins, leukotrienes, HETES,

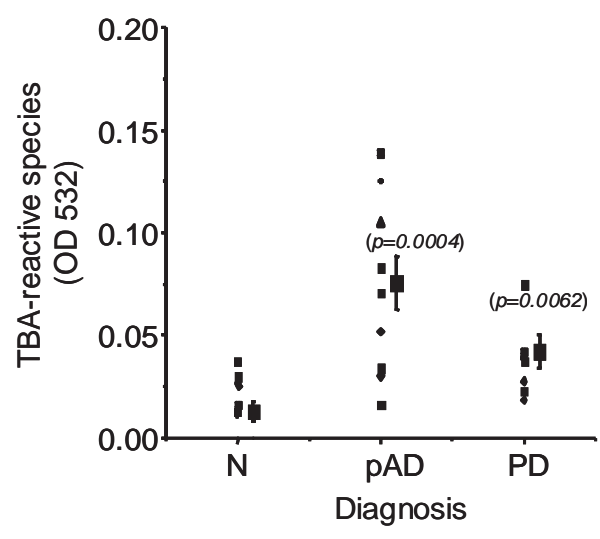

Fig. 10. Thiobarbituric acid-reactive products in urine from normal, $\mathrm{AD}$ and PD subjects- Urine samples from normal $(\mathrm{N}, n=9)$, probable $\mathrm{AD}(\mathrm{pAD}, n=19)$ or from PD $(n=5)$ subjects were reacted with TBA. The OD at $532 \mathrm{~nm}$ was obtained. The mean OD for each group was obtained and comparison between groups was performed using non-parametric statistics for unpaired data. The $\mathrm{p}$ values for pAD versus $\mathrm{N}$ and $\mathrm{PD}$ versus $\mathrm{N}$ are indicated.

isoprostanes) and their fatty acid precursors in human CSF. As shown by Fig. 7, several eicosanoids are present in CSF. Total ion monitoring in combination with chromatographic methods (chiral phase chromatography or GC) will likely reveal hundreds if not thousands of isomers derived from many PUFAs in CSF. Overall, our knowledge of lipidomics in combination with free radical chemistry or with proteomics should increase our understanding about the formation of oxidized lipids and their utility as potential disease markers.

\section{An overview of brain pathology and lipids}

In examining the structure, biosynthesis and importance of lipids in the CNS, several biochemical pathways and mechanisms were proposed for their role in pathophysiology. The major pathways involve lipid biosynthesis, oxidative and structural damage of lipids, lipid transport and formation of signaling molecules (Fig. 9). Lipids from the diet or obtained from de novo synthesis are transported and catabolized in the brain. Transport is affected by lipoproteins, lipoprotein receptors, albumin and binding proteins such as PGDS/lipocalin. Lipids are transported to sites where they are needed for nerve cell regeneration or for secretion of transmitters. When the brain is under stress due to infection, trauma or environmental factors, lipids are also metabolized by oxygenases. Simultaneously, lipids that control ion channels, induce inflammation, 
sleep or control pain may be formed. Lipids can be controlled at the various points of this metabolic chain. Impairment at any level may result in destabilization of metabolic processes manifested by pathologic processes linked to brain diseases. An accurate measure of lipids or proteins that bind/transport or metabolize lipids can help uncover what has precipitated the neurodegenerative processes in the brain.

\section{Conclusions}

PUFAs, cholesterol, phospholipids and enzymes that metabolize these lipids are important in brain function. Processes that control lipid metabolism are altered in several brain diseases. Measurement of lipid composition and examination of enzyme activity or protein levels may constitute a multiplex approach for discovering how defects in lipid metabolism affect brain physiology. Our studies involving a combination of lipidomics and proteomics of CSF have started to reveal how lipidrelated proteins may be linked to disease pathology. Lipids, their oxidized products or signaling molecules are implicated in disease mechanisms (inflammation, oxidation, pain), and physiologic processes (sleep, release of neurotransmitters or induction of signaling cascades). Discovery of lipid pathways and elucidation of mechanisms will provide not only an indication of what may be wrong as a disease process is initiated, but preempt strategies to control, prevent or alleviate symptoms of diseases.

For example, dietary supplements using PUFAenriched fish oils, antioxidants that prevent oxidation of PUFAs or specific inhibitors of enzymes may be indicated once defects in lipid specific pathways have been discovered.

\section{Acknowledgment}

We thank all Molecular Neurology Program study participants for their time and for donating CSF. This work is supported by funds from the National Institutes of Health (RO1\#11020991), and the Dunlevy, Posthuma and Norris foundations.

\section{References}

[1] J.J. Albers, V.G. Cabana and S.Y. Dee Barden, Purification and characterization of human plasma lecithin: cholesterol acyltransferase, Biochemistry 15 (1976), 1084-1087.
[2] J.J. Albers, S.M. Marcovina and R.H. Christenson, Lecithin cholesterol acyltransferase in human cerebrospinal fluid: reduced level in patients with multiple sclerosis and evidence of direct synthesis in the brain, Int J Clin Lab Res 22 (1992), 169-172.

[3] E. Alger, Retrograde signaling in the regulation of synaptic transmission: focus on endocannabinoids, Progress in Neurobiology 68 (2002), 247-286.

[4] H. Arai, Platelet-activating factor acetylhydrolase, Prostaglandins Other Lipid Mediat 68-69 (2002), 83-94.

[5] K. Asai, T. Hirabayashi, T. Houjou, N. Uozumi, R. Taguchi and T. Shimizu, Human group IVC phospholipase $\mathrm{A}_{2}$ (cPLA 2 gamma). Roles in the membrane remodeling and activation induced by oxidative stress, J Biol Chem 278 (2003), 8809-8814.

[6] M. Balazy, Eicosanomics: targeted lipidomics of eicosanoids in biological systems, Prostaglandins Other Lipid Mediat 73 (2004), 173-180.

[7] M. Balazy and R.C. Murphy, Determination of sulfidopeptide leukotrienes in biological fluids by gas chromatography/mass spectrometry, Anal Chem 58 (1986), 1098-1101.

[8] G. Baltas, H. Kotsifaki, S. Antonopoulou, A. Kipioti and C.A. Demopoulos, Implication of PAF and acetylhydrolase (PAF$\mathrm{AH})$ activity in periodontal disease, Adv Exp Med Biol 416 (1996), 135-141.

[9] G.L. Bannenberg, N. Chiang, A. Ariel, M. Arita, E. Tjonahen, K.H. Gotlinger, S. Hong and C.N. Serhan, Molecular Circuits of Resolution: Formation and Actions of Resolvins and Protectins, J Immunol 174 (2005), 4345-4355.

[10] E.E. Baulieu, Neurosteroids: a new function in the brain, Biol Cell 71 (1991), 3-10.

[11] E.E. Baulieu, Neurosteroids: a novel function of the brain, Psychoneuroendocrinology 23 (1998), 963-987.

[12] N.G. Bazan, Bioactive lipids and gene expression in neuronal plasticity, Adv Exp Med Biol 446 (1997), 37-49.

[13] N.G. Bazan, COX-2 as a multifunctional neuronal modulator, Nat Med 7 (2001), 414-415.

[14] N.G. Bazan, Synaptic lipid signaling: significance of polyunsaturated fatty acids and platelet-activating factor, J Lipid Res 44 (2003), 2221-2233.

[15] N.G. Bazan, V. Colangelo and W.J. Lukiw, Prostaglandins and other lipid mediators in Alzheimer's disease, Prostaglandins Other Lipid Mediat 68-69 (2002), 197-210.

[16] N.G. Bazan and W.J. Lukiw, Cyclooxygenase-2 and presenilin-1 gene expression induced by interleukin-1beta and amyloid beta 42 peptide is potentiated by hypoxia in primary human neural cells, J Biol Chem 277 (2002), 30359-30367.

[17] U. Beffert, P.C. Stolt and J. Herz, Functions of lipoprotein receptors in neurons, J Lipid Res 45 (2004), 403-409.

[18] U. Beisiegel and A.A. Spector, Lipids and lipoproteins in the brain, Curr Opin Lipidol 12 (2001), 243-244.

[19] L. Belayev, V.L. Marcheselli, L. Khoutorova, E.B. Rodriguez de Turco, R. Busto, M.D. Ginsberg and N.G. Bazan, Docosahexaenoic acid complexed to albumin elicits high-grade ischemic neuroprotection, Stroke 36 (2005), 118-123.

[20] J.G. Bell, E.E. MacKinlay, J.R. Dick, D.J. Macdonald, R.M. Boyle and A.C. Glen, Essential fatty acids and phospholipase $\mathrm{A}_{2}$ in autistic spectrum disorders, Prostaglandins Leukot Essent Fatty Acids 71 (2004), 201-204.

[21] M.J. Berridge, Receptor-stimulated inositol phospholipid hydrolysis and neural function, Biochem Soc Symp 52 (1986), 153-161.

[22] M.J. Berridge, Neuronal calcium signaling, Neuron 21 (1998), 13-26. 
[23] S. Bhamre, H.K. Anandatheerthavarada, S.K. Shankar and V. Ravindranath, Microsomal cytochrome P450 in human brain regions, Biochem Pharmacol 44 (1992), 1223-1225.

[24] I. Bjorkhem and S. Meaney, Brain cholesterol: long secret life behind a barrier, Arterioscler Thromb Vasc Biol 24 (2004), 806-815.

[25] S. Bluml, M. Philippart, R. Schiffmann, K. Seymour and B.D. Ross, Membrane phospholipids and high-energy metabolites in childhood ataxia with CNS hypomyelination, Neurology 61 (2003), 648-654

[26] S. Bluml, K.J. Seymour and B.D. Ross, Developmental changes in choline- and ethanolamine-containing compounds measured with proton-decoupled (31)P MRS in in vivo human brain, Magn Reson Med 42 (1999), 643-654.

[27] S. Bodovitz and W.L. Klein, Cholesterol modulates alphasecretase cleavage of amyloid precursor protein, J Biol Chem 271 (1996), 4436-4440.

[28] N. Bogdanovic, L. Bretillon, E.G. Lund, U. Diczfalusy, L. Lannfelt, B. Winblad, D.W. Russell and I. Bjorkhem, On the turnover of brain cholesterol in patients with Alzheimer's disease. Abnormal induction of the cholesterol-catabolic enzyme CYP46 in glial cells, Neurosci Lett 314 (2001), 45-48.

[29] J.M. Bourre, M. Bonneil, M. Clement, O. Dumont, G. Durand, H. Lafont, G. Nalbone and M. Piciotti, Function of dietary polyunsaturated fatty acids in the nervous system, Prostaglandins Leukot Essent Fatty Acids 48 (1993), 5-15.

[30] C.J. Brame, R.G. Salomon, J.D. Morrow and L.J. Roberts, Identification of extremely reactive gamma-ketoaldehydes (isolevuglandins) as products of the isoprostane pathway and characterization of their lysyl protein adducts, $\mathrm{J}$ Biol Chem 274 (1999), 13139-13146.

[31] P. Braquet, B. Spinnewyn, N. Blavet, V. Marcheselli, M. Rossawska and N.G. Bazan, Platelet activating factor as a mediator in cerebral ischemia and related disorders, Biomed Biochim Acta 47 (1988), S195-S218.

[32] P.M. Bretsky, J.G. Buckwalter, T.E. Seeman, C.A. Miller, J. Poirier, G.D. Schellenberg, C.E. Finch and V.W. Henderson, Evidence for an interaction between apolipoprotein E genotype, gender, and Alzheimer disease, Alzheimer Dis Assoc Disord 13 (1999), 216-221.

[33] J. Brown III, C. Theisler, S. Silberman, D. Magnuson, N. Gottardi-Littell, J.M. Lee, D. Yager, J. Crowley, K. Sambamurti, M.M. Rahman, A.B. Reiss, C.B. Eckman and B. Wolozin, Differential expression of cholesterol hydroxylases in Alzheimer's disease, J Biol Chem 279 (2004), 3467434681 .

[34] W.C. Byrdwell, Dual parallel mass spectrometers for analysis of sphingolipid, glycerophospholipid and plasmalogen molecular species, Rapid Commun Mass Spectrom 12 (1998), 256272.

[35] W.C. Byrdwell, Atmospheric pressure chemical ionization mass spectrometry for analysis of lipids, Lipids 36 (2001), 327-346.

[36] W.C. Byrdwell and E.A. Emken, Analysis of triglycerides using atmospheric pressure chemical ionization mass spectrometry, Lipids 30 (1995), 173-175.

[37] L. Callea, M. Arese, A. Orlandini, C. Bargnani, A. Priori and F. Bussolino, Platelet activating factor is elevated in cerebral spinal fluid and plasma of patients with relapsing-remitting multiple sclerosis, J Neuroimmunol 94 (1999), 212-221.

[38] Y. Cao, E. Traer, G.A. Zimmerman, T.M. McIntyre and S.M. Prescott, Cloning, expression, and chromosomal localization of human long-chain fatty acid-CoA ligase 4 (FACL4), $\mathrm{Ge}$ nomics 49 (1998), 327-330.
[39] J.G. Chamberlain, Dietary lipids and evolution of the human brain, Br J Nutr 80 (1998), 301-302.

[40] D. Chapman, The role of fatty acids in myelin and other important brain structures. In: lipids, malnutrition \& the developing brain, Ciba Found Symp (1971), 31-57.

[41] M.C. Chartier-Harlin, M. Parfitt, S. Legrain, J. Perez-Tur, T. Brousseau, A. Evans, C. Berr, O. Vidal, P. Roques and V. Gourlet, Apolipoprotein E, epsilon 4 allele as a major risk factor for sporadic early and late-onset forms of Alzheimer's disease: analysis of the $19 \mathrm{q} 13.2$ chromosomal region, Hum Mol Genet 3 (1994), 569-574.

42] D. Chelius, A.F. Huhmer, C.H. Shieh, E. Lehmberg, J.A. Traina, T.K. Slattery and E. Pungor, Jr, Analysis of the adenovirus type 5 proteome by liquid chromatography and tandem mass spectrometry methods, J Proteome Res 1 (2002), 501-513.

[43] E. Chieregatti and J. Meldolesi, Regulated exocytosis: new organelles for non-secretory purposes, Nat Rev Mol Cell Biol 6 (2005), 181-187.

[44] F.H. Chilton III. and R.C. Murphy, Fast atom bombardment analysis of arachidonic acid-containing phosphatidylcholine molecular species, Biomed Environ Mass Spectrom 13 (1986), 71-76.

[45] S.S. Chuang, C. Helvig, M. Taimi, H.A. Ramshaw, A.H. Collop, M. Amad, J.A. White, M. Petkovich, G. Jones and B. Korczak, CYP2U1, a novel human thymus- and brainspecific cytochrome P450, catalyzes omega- and (omega-1)hydroxylation of fatty acids, J Biol Chem 279 (2004). 63056314.

[46] K.L. Clay, R.C. Murphy, J.L. Andres, J. Lynch and P.M. Henson, Structure elucidation of platelet activating factor derived from human neutrophils, Biochem Biophys Res Commun 121 (1984), 815-825.

[47] J.A. Clemens, D.T. Stephenson, E.B. Smalstig, E.F. Roberts, E.M. Johnstone, J.D. Sharp, S.P. Little and R.M. Kramer, Reactive glia express cytosolic phospholipase A2 after transient global forebrain ischemia in the rat, Stroke 27 (1996), 527535.

[48] S. Cockcroft, ARF-regulated phospholipase D: a potential role in membrane traffic, Chem Phys Lipids 80 (1996), 59-80.

[49] S. Cockcroft, Phosphatidylinositol transfer proteins: requirements in phospholipase $\mathrm{C}$ signaling and in regulated exocytosis, FEBS Lett 410 (1997), 44-48.

[50] S. Cockcroft, Mammalian phosphatidylinositol transfer proteins: emerging roles in signal transduction and vesicular traffic, Chem Phys Lipids 98 (1999), 23-33.

[51] S. Cockcroft, Signalling roles of mammalian phospholipase D1 and D2, Cell Mol Life Sci 58 (2001), 1674-1687.

[52] O. Cremona, G. Di Paolo, M.R. Wenk, A. Luthi, W.T. Kim, K. Takei, L. Daniell, Y. Nemoto, S.B. Shears, R.A. Flavell, D.A. McCormick and P. De Camilli, Essential role of phosphoinositide metabolism in synaptic vesicle recycling, Cell 99 (1999), 179-188.

[53] M. Danik, D. Champagne, C. Petit-Turcotte, U. Beffert and J. Poirier, Brain lipoprotein metabolism and its relation to neurodegenerative disease, Crit Rev Neurobiol 13 (1999), 357407.

[54] U.N. Das, Essential fatty acids in health and disease, $J$ Assoc Physicians India 47 (1999), 906-911.

[55] P. De Camilli, Exocytosis goes with a SNAP, Nature 364 (1993), 387-388.

[56] A. de Gassart, C. Geminard, B. Fevrier, G. Raposo and M. Vidal, Lipid raft-associated protein sorting in exosomes, Blood 102 (2003), 4336-4344. 
[57] L. De Petrocellis, D. Melck, T. Bisogno and M.V. Di, Endocannabinoids and fatty acid amides in cancer, inflammation and related disorders, Chem Phys Lipids 108 (2000), 191-209.

[58] P.P. Di Fiore and P. De Camilli, Endocytosis and signaling, an inseparable partnership, Cell 106 (2001), 1-4.

[59] G. Di Paolo, H.S. Moskowitz, K. Gipson, M.R. Wenk, S. Voronov, M. Obayashi, R. Flavell, R.M. Fitzsimonds, T.A. Ryan and P. De Camilli, Impaired PtdIns(4,5)P2 synthesis in nerve terminals produces defects in synaptic vesicle trafficking, Nature 431 (2004), 415-422.

[60] J.M. Dietschy and S.D. Turley, Cholesterol metabolism in the brain, Curr Opin Lipidol 12 (2001), 105-112.

[61] J.M. Dietschy and S.D. Turley, Thematic review series: brain Lipids, Cholesterol metabolism in the central nervous system during early development and in the mature animal, J Lipid Res 45 (2004), 1375-1397.

[62] G. Du, P. Huang, B.T. Liang and M.A. Frohman, Phospholipase D2 localizes to the plasma membrane and regulates angiotensin II receptor endocytosis, Mol Biol Cell 15 (2004), 1024-1030.

[63] A. Ducret, O.I. Van, J.K. Eng, J.R. Yates III. and R. Aebersold, High throughput protein characterization by automated reverse-phase chromatography/electrospray tandem mass spectrometry, Protein Sci 7 (1998), 706-719.

[64] G.P. Eckert, C. Kirsch and W.E. Muller, Brain-membrane cholesterol in Alzheimer's disease, J Nutr Health Aging 7 (2003), 18-23.

[65] C. Edlund, K. Holmberg, G. Dallner, E. Norrby and K. Kristensson, Ubiquinone-10 protects neurons from virus-induced degeneration, J Neurochem 63 (1994), 634-639.

[66] C. Edlund, M. Soderberg, K. Kristensson and G. Dallner, Ubiquinone, dolichol, and cholesterol metabolism in aging and Alzheimer's disease, Biochem Cell Biol 70 (1992), 422-428.

[67] P.L. Else and A.J. Hulbert, Membranes as metabolic pacemakers, Clin Exp Pharmacol Physiol 30 (2003), 559-564.

[68] E. Fahy, S. Subramaniam, H.A. Brown, C.K. Glass, A.H. Merrill, Jr, R.C. Murphy, C.R. Raetz, D.W. Russell, Y. Seyama, W. Shaw, T. Shimizu, F. Spener, G. van Meer, M.S. Vannieuwenhze, S.H. White, J. Witztum and E.A. Dennis, A comprehensive classification system for lipids, J Lipid Res (2005).

[69] A. Farooqui, L. Horrocks and T. Farooqui, Glycerophospholipids in brain: their metabolism, incorporation into membranes, functions, and involvement in neurological disorders, Chemistry and Physics of Lipids 106 (2000), 1-29.

[70] A.A. Farooqui and L.A. Horrocks, Plasmalogen-selective phospholipase A2 and its involvement in Alzheimer's disease, Biochem Soc Trans 26 (1998), 243-246.

[71] A.A. Farooqui, L.A. Horrocks and T. Farooqui, Deacylation and reacylation of neural membrane glycerophospholipids, $J$ Mol Neurosci 14 (2000), 123-135.

[72] A.A. Farooqui, M.L Litsky, T. Farooqui and L.A. Horrocks, Inhibitors of intracellular phospholipase $\mathrm{A}_{2}$ activity: their neurochemical effects and therapeutical importance for neurological disorders [In Process Citation], Brain Res Bull 49 (1999), 139-153.

[73] A.A. Farooqui, H.C. Yang, T.A. Rosenberger and L.A. Horrocks, Phospholipase A2 and its role in brain tissue, $\mathrm{J} \mathrm{Neu-}$ rochem 69 (1997), 889-901.

[74] K. Farsad and P. De Camilli, Neurotransmission and the synaptic vesicle cycle, Yale J Biol Med 75 (2002), 261-284

[75] B. Fevrier, D. Vilette, F. Archer, D. Loew, W. Faigle, M. Vidal, H. Laude and G. Raposo, Cells release prions in association with exosomes, Proc Natl Acad Sci USA 101 (2004), 96839688 .
[76] A.N. Fonteh, Assessment of arachidonic acid distribution into phospholipids of inflammatory cells, Methods Mol Biol 120 (1999), 77-89.

[77] A.N. Fonteh, Differential effects of arachidonoyl trifluoromethyl ketone on arachidonic acid release and lipid mediator biosynthesis by human neutrophils, Evidence for different arachidonate pools, Eur J Biochem 269 (2002), 3760-3770.

[78] A.N. Fonteh, An outline of arachidonate remodeling and its biological significance, in: Arachidonate Remodeling and Inflammation, A.N. Fonteh and R.L. Wykle, eds, Birkhauser Verlag, 2004, pp. 1-11.

[79] A.N. Fonteh and F.H. Chilton, Rapid remodeling of arachidonate from phosphatidylcholine to phosphatidylethanolamine pools during mast cell activation, J Immunol 148 (1992), 1784-1791.

[80] A.N. Fonteh, R. Cowan and M.G. Harrington, Importance of proteins that metabolize polyunsaturated fatty acids in the pathogenesis of Alzheimer's disease 91 (2002), 5th Siena Conference on Functional Proteomics.

[81] A.N. Fonteh and M.G. Harrington, Ictal and interictal changes in proteins that metabolize fatty acids in cerebrospinal fluids of migraineurs and control subjects 259 (2002), 5th Siena conference on Functional Proteomics,

[82] A.N. Fonteh and M.G. Harrington, Remodeling of arachidonate and other polyunsaturated fatty acids in Alzheimer's disease, in: Arachidonate Remodeling and Inflammation, A.N. Fonteh and R.L. Wykle, eds, Birkhauser Verlag, 2004, pp. $145-168$.

[83] A.N. Fonteh, R.J. Harrington and M.G. Harrington, Use of liquid chromatography and tandem mass spectrometry to measure metabolites in human cerebrospinal fluids, Neuroscience (2004), 695.7. 2004.

[84] A.N. Fonteh, T. LaPorte, D. Swan and M.A. McAlexander, A decrease in remodeling accounts for the accumulation of arachidonic acid in murine mast cells undergoing apoptosis, $J$ Biol Chem 276 (2001), 1439-1449.

[85] G. Galli, E.G. Paoletti and J.F. Weiss, Sterol precursors of cholesterol in adult human brain, Science 162 (1968), 14951496.

[86] R.A. Gibson and M. Makrides, Long-chain polyunsaturated fatty acids in breast milk: are they essential? Adv Exp Med Biol 501 (2001), 375-383.

[87] E. Grossi, P. Paoletti and R. Paoletti, An analysis of brain cholesterol and fatty acid biosynthesis, Arch Int Physiol Biochim 66 (1958), 564-572.

[88] M.I. Gurr, Dietary lipids and evolution of the human brain, $\mathrm{Br}$ J Nutr 79 (1998), 389-392.

[89] J.S. Hadley, A. Fradin and R.C. Murphy, Electron capture negative ion chemical ionization analysis of arachidonic acid, Biomed Environ Mass Spectrom 15 (1988), 175-178.

[90] X. Han and H. Cheng, Characterization and direct quantitation of cerebroside molecular species from lipid extracts by shotgun lipidomics, J Lipid Res 46 (2005), 163-175.

[91] X. Han and R.W. Gross, Shotgun lipidomics: Electrospray ionization mass spectrometric analysis and quantitation of cellular lipidomes directly from crude extracts of biological samples, Mass Spectrom Rev 24 (2005), 367-412.

[92] M.G. Harrington and C.R. Merril, Two-dimensional electrophoresis and ultrasensitive silver staining of cerebrospinal fluid proteins in neurological diseases, Clin Chem 30 (1984), 1933-1937.

[93] E.J. Hartman, S. Omura and M. Laposata, Triacsin C: a differential inhibitor of arachidonoyl-CoA synthetase and non- 
specific long chain acyl-CoA synthetase, Prostaglandins $\mathbf{3 7}$ (1989), 655-671.

[94] R.J. Harvey, U.B. Depner, H. Wassle, S. Ahmadi, C. Heindl, H. Reinold, T.G. Smart, K. Harvey, B. Schutz, O.M. Abo-Salem, A. Zimmer, P. Poisbeau, H. Welzl, D.P. Wolfer, H. Betz, H.U. Zeilhofer and U. Muller, GlyR alpha3: an essential target for spinal PGE2-mediated inflammatory pain sensitization, Science 304 (2004), 884-887.

[95] O. Hayaishi, Molecular mechanisms of sleep-wake regulation: a role of prostaglandin D2, Philos Trans R Soc Lond B Biol Sci 355 (2000), 275-280.

[96] R. Heipertz, H. Pilz, D. Seidel, W. Klauke and H.H. Goebel, Fatty acid composition of myelin lipids (cerebrosides, sulphatides and sphingomyelin) from normal human sural nerve, and changes in peripheral neuropathy, Neuropathol Appl Neurobiol 4 (1978), 197-207.

[97] A. Heller, T. Koch, J. Schmeck and K. van Ackern, Lipid mediators in inflammatory disorders, Drugs 55 (1998), 487496.

[98] A.L. Henneberry and C.R. McMaster, Cloning and expression of a human choline/ethanolaminephosphotransferase: synthesis of phosphatidylcholine and phosphatidylethanolamine, Biochem J 339(Pt 2) (1999), 291-298.

[99] J. Herbert, Neurosteroids, brain damage, and mental illness, Exp Gerontol 33 (1998), 713-727.

[100] C. Hillard, Biochemistry and pharmacology of the endocannabinoids arachidonylethanolamide and 2-arachidonylglycerol, Prostaglandins and Other Lipid Mediators 61 (2000), 3-18.

[101] D.F. Hochstrasser, M.G. Harrington, A.C. Hochstrasser, M.J. Miller and C.R. Merril, Methods for increasing the resolution of two-dimensional protein electrophoresis, Anal Biochem 173 (1988), 424-435.

[102] T. Houjou, K. Yamatani, M. Imagawa, T. Shimizu and R. Taguchi, A shotgun tandem mass spectrometric analysis of phospholipids with normal-phase and/or reverse-phase liquid chromatography/electrospray ionization mass spectrometry, Rapid Commun Mass Spectrom 19 (2005), 654-666.

[103] L.A. Howard, E.M. Sellers and R.F. Tyndale, The role of pharmacogenetically-variable cytochrome P450 enzymes in drug abuse and dependence, Pharmacogenomics 3 (2002), 185-199.

[104] A.F. Huhmer, R.G. Biringer, H. Amato and M.G. Harrington, Shotgun sequencing of the human cerebrospinal fluid proteome using $2 D$ chromatography in combination with linear ion trap mass spectrometry, Proteomic Forum, Munich Germany, 2003.

[105] A.N. Hunt, J.G. Alb, G. Koster, A.D. Postle and V.A. Bankaitis, Use of mass spectrometry-based lipidomics to probe PITPalpha (phosphatidylinositol transfer protein alpha) function inside the nuclei of PITPalpha $+/+$ and PITPalpha-/- cells, Biochem Soc Trans 32 (2004), 10631065.

[106] A.N. Hunt, H.C. Fenn, G.T. Clark, M.M. Wright, A.D. Postle and C.R. McMaster, Lipidomic analysis of the molecular specificity of a cholinephosphotransferase in situ, Biochem Soc Trans 32 (2004), 1060-1062.

[107] J.H. Hwang, S. Bluml, A. Leaf and B.D. Ross, In vivo characterization of fatty acids in human adipose tissue using natural abundance ${ }^{1} \mathrm{H}$ decoupled ${ }^{13} \mathrm{C}$ MRS at $1.5 \mathrm{~T}$ : clinical applications to dietary therapy, NMR Biomed 16 (2003), 160-167.

[108] P.T. Ivanova, S.B. Milne, J.S. Forrester and H.A. Brown, LIPID Arrays: New Tools in the Understanding of Membrane Dynamics and Lipid Signaling, Mol Interv 4 (2004), 86-96.
[109] T.J. Jeerakathil and P.A. Wolf, Prevention of strokes, Curr Atheroscler Rep 3 (2001), 321-327.

[110] A. Jonas, Lecithin cholesterol acyltransferase, Biochimica et Biophysica Acta (BBA)/Molecular and Cell Biology of Lipids 1529 (2000), 245-256.

[111] D. Jones, C. Morgan and S. Cockcroft, Phospholipase D and membrane traffic. Potential roles in regulated exocytosis, membrane delivery and vesicle budding, Biochim Biophys Acta 1439 (1999), 229-244.

[112] H. Jurevics and P. Morell, Cholesterol for synthesis of myelin is made locally, not imported into brain, J Neurochem 64 (1995), 895-901.

[113] J.J. Kabara and B. Chapman, Brain cholesterol. XV. Incorporation of specifically labeled glucose, Lipids 7 (1972), 692694.

[114] K. Karasawa, A. Harada, N. Satoh, K. Inoue and M. Setaka, Plasma platelet activating factor-acetylhydrolase (PAF-AH), Prog Lipid Res 42 (2003), 93-114.

[115] R. Katz, J.A. Hamilton, A.A. Spector, S.A. Moore, H.W. Moser, M.J. Noetzel and P.A. Watkins, Brain uptake and utilization of fatty acids: recommendations for future research, J Mol Neurosci 16 (2001), 333-335.

[116] S. Kawato, M. Yamada and T. Kimoto, Brain neurosteroids are 4th generation neuromessengers in the brain: cell biophysical analysis of steroid signal transduction, Adv Biophys $\mathbf{3 7}$ (2003), 1-48.

[117] K.A. Kayganich-Harrison and R.C. Murphy, Characterization of chain-shortened oxidized glycerophosphocholine lipids using fast atom bombardment and tandem mass spectrometry, Anal Biochem 221 (1994), 16-24.

[118] R.A. Kelly, D.S. O'Hara, W.E. Mitch and T.W. Smith, Identification of NaK-ATPase inhibitors in human plasma as nonesterified fatty acids and lysophospholipids, J Biol Chem $\mathbf{2 6 1}$ (1986), 11704-11711.

[119] S.Y. Kim, d.S. Min, J.S. Choi, Y.S. Choi, H.J. Park, K.W. Sung, J. Kim and M.Y. Lee, Differential expression of phospholipase D isozymes in the hippocampus following kainic acid-induced seizures, J Neuropathol Exp Neurol 63 (2004), $812-820$.

[120] C. Kirsch, G.P. Eckert, A.R. Koudinov and W.E. Muller, Brain cholesterol, statins and Alzheimer's Disease, Pharmacopsychiatry 36(2) (2003), S113-S119.

[121] R.M. Kramer and D. Deykin, Arachidonoyl transacylase in human platelets. Coenzyme A-independent transfer of arachidonate from phosphatidylcholine to lysoplasmenylethanolamine, J Biol Chem 258 (1983), 13806-13811.

[122] R.M. Kramer, J.A. Jakubowski and D. Deykin, Hydrolysis of 1-alkyl-2-arachidonoyl-sn-glycero-3-phosphocholine, a common precursor of platelet-activating factor and eicosanoids, by human platelet phospholipase A2, Biochim Biophys Acta 959 (1988), 269-279.

[123] I. Kudo and M. Murakami, Phospholipase $A_{2}$ enzymes, Prostaglandins and Other Lipid Mediators 68-69 (2002), 358.

[124] F. Lai, E. Kammann, G.W. Rebeck, A. Anderson, Y. Chen and R.A. Nixon, APOE genotype and gender effects on Alzheimer disease in 100 adults with Down syndrome, Neurology 53 (1999), 331-336.

[125] W.E. Lands, Biochemistry and physiology of n-3 fatty acids, FASEB J 6 (1992), 2530-2536.

[126] W.E. Lands and P. Hart, Metabolism of glycerolipids. VI. Specificities of acyl coenzyme A: phospholipid acyltransferases, J Biol Chem 240 (1965), 1905-1911. 
[127] R.A. Lasser, R. Dukoff, J. Levy, R. Levin, T. Lehtimaki, P. Seubert and T. Sunderland, Apolipoprotein E epsilon 4 allele in association with global cognitive performance and CSF markers in Alzheimer's disease, Int J Geriatr Psychiatry 13 (1998), 767-774.

[128] H. Le Stunff, I. Galve-Roperh, C. Peterson, S. Milstien and S. Spiegel, Sphingosine-1-phosphate phosphohydrolase in regulation of sphingolipid metabolism and apoptosis, J Cell Biol 158 (2002), 1039-1049.

[129] S.H. Lee, M.V. illiams, R.N. DuBois and I.A. Blair, Targeted lipidomics using electron capture atmospheric pressure chemical ionization mass spectrometry, Rapid Commun Mass Spectrom 17 (2003), 2168-2176.

[130] J. Li and R.J. Wurtman, Heterogeneous long chain acylCoA synthetases control distribution of individual fatty acids in newly-formed glycerolipids of neuronal cells undergoing neurite outgrowth, Neurochem Res 24 (1999), 739-750.

[131] M. Liu, P.D. Hurn and N.J. Alkayed, Cytochrome P450 in neurological disease, Curr Drug Metab 5 (2004), 225-234.

[132] S. Liu, J. Sjovall and W.J. Griffiths, Neurosteroids in rat brain: extraction, isolation, and analysis by nanoscale liquid chromatography-electrospray mass spectrometry, Anal Chem 75 (2003), 5835-5846.

[133] Y. Lu, S. Hong, E. Tjonahen and C.N. Serhan, Mediatorlipidomics: databases and search algorithms for PUFAderived mediators, J Lipid Res 46 (2005), 790-802.

[134] G. Lucotte, A. Aouizerate, N. Gerard, J.C. Turpin and P. Landais, Allele doses of apolipoprotein $\mathrm{E}$ type epsilon 4 in sporadic late-onset Alzheimer's disease, Am J Med Genet 60 (1995), 566-569.

[135] D. Lutjohann, O. Breuer, G. Ahlborg, I. Nennesmo, A. Siden, U. Diczfalusy and I. Bjorkhem, Cholesterol homeostasis in human brain: evidence for an age-dependent flux of $24 \mathrm{~S}$ hydroxycholesterol from the brain into the circulation, Proc Natl Acad Sci USA 93 (1996), 9799-9804.

[136] D. Lutjohann and K. von Bergmann, 24S-hydroxycholesterol: a marker of brain cholesterol metabolism, Pharmacopsychiatry 36(2) (2003), S102-S106.

[137] J.R. Lynch, W. Tang, H. Wang, M.P. Vitek, E.R. Bennett, P.M. Sullivan, D.S. Warner and D.T. Laskowitz, APOE genotype and an ApoE-mimetic peptide modify the systemic and central nervous system inflammatory response, $J$ Biol Chem 278 (2003), 48529-48533.

[138] S. Maekawa, S. Iino and S. Miyata, Molecular characterization of the detergent-insoluble cholesterol-rich membrane microdomain (raft) of the central nervous system, Biochimica et Biophysica Acta (BBA)/Biomembranes 1610 (2003), 261-270.

[139] V.L. Marcheselli, S. Hong, W.J. Lukiw, X.H. Tian, K. Gronert, A. Musto, M. Hardy, J.M. Gimenez, N. Chiang, C.N. Serhan and N.G. Bazan, Novel docosanoids inhibit brain ischemia-reperfusion-mediated leukocyte infiltration and proinflammatory gene expression, J Biol Chem 278 (2003), 43807-43817.

[140] W.R. Markesbery and J.M. Carney, Oxidative alterations in Alzheimer's disease, Brain Pathol 9 (1999), 133-146.

[141] L.J. Marnett, T.L. Wright, B.C. Crews, S.R. Tannenbaum and J.D. Morrow, Regulation of prostaglandin biosynthesis by nitric oxide is revealed by targeted deletion of inducible nitric-oxide synthase, J Biol Chem 275 (2000), 13427-13430.

[142] M. Martinez and I. Mougan, Fatty acid composition of human brain phospholipids during normal development, J Neurochem 71 (1998), 2528-2533.

[143] R.P. Mason, W.J. Shoemaker, L. Shajenko, T.E. Chambers and L.G. Herbette, Evidence for changes in the Alzheimer's disease brain cortical membrane structure mediated by cholesterol, Neurobiol Aging 13 (1992), 413-419.

144] N. Mast, R. Norcross, U. Andersson, M. Shou, K. Nakayama, I. Bjorkhem and I.A. Pikuleva, Broad substrate specificity of human cytochrome P450 46A1 which initiates cholesterol degradation in the brain, Biochemistry 42 (2003), 1428414292.

145] Y. Masuzawa, T. Sugiura, H. Sprecher and K. Waku, Selective acyl transfer in the reacylation of brain glycerophospholipids. Comparison of three acylation systems for 1alk-1'-enylglycero-3-phosphoethanolamine, 1-acylglycero-3phosphoethanolamine and 1-acylglycero-3-phosphocholine in rat brain microsomes, Biochim Biophys Acta 1005 (1989), $1-12$.

[146] M.A. McAlexander, B.J. Barham, M.M. Johnson and A.N. Fonteh, Control of long chain polyunsaturated fatty acid levels and the role of inhibitors of incorporation and remodeling on the biosynthesis of lipid mediators, in: Arachidonate Remodeling and Infammation, A.N. Fonteh and R.L. Wykle, eds, Birkhauser Verlag, 2004, pp. 89-130.

[147] M. McDermott, M.J. Wakelam and A.J. Morris, Phospholipase D, Biochem Cell Biol 82 (2004), 225-253.

[148] S.L. Miksys and R.F. Tyndale, Drug-metabolizing cytochrome P450s in the brain, J Psychiatry Neurosci 27 (2002), 406-415.

[149] L.G. Miller, N.G. Bazan, R.B. Roy, F. Clostre, A. Gaver and P. Braquet, Platelet activating factor antagonists interact with GABAA receptors, Res Commun Chem Pathol Pharmacol 74 (1991), 253-256.

[150] K.S. Montine, S.J. Olson, V. Amarnath, W.O. Whetsell Jr., D.G. Graham and T.J. Montine, Immunohistochemical detection of 4-hydroxy-2-nonenal adducts in Alzheimer's disease is associated with inheritance of APOE4, Am J Pathol 150 (1997), 437-443

[151] T.J. Montine, M.F. Beal, M.E. Cudkowicz, H. O'Donnell, R.A. Margolin, L. McFarland, A.F. Bachrach, W.E. Zackert, L.J. Roberts and J.D. Morrow, Increased CSF F2-isoprostane concentration in probable AD, Neurology 52 (1999), 562-565.

[152] T.C. Moon, M.S. Kim, S.J. Lee, T.Y. Lee, S.H. Kwon, S.H. Baek and H.W. Chang, Detection and characterization of $45 \mathrm{kDa}$ platelet activating factor acetylhydrolase in cerebrospinal fluid of children with meningitis, Arch Pharm Res 26 (2003), 554-558.

[153] A.N. Moore, A.W. Kampfl, X. Zhao, R.L. Hayes and P.K. Dash, Sphingosine-1-phosphate induces apoptosis of cultured hippocampal neurons that requires protein phosphatases and activator protein-1 complexes, Neuroscience 94 (1999), 405415.

[154] J.D. Morrow, The isoprostanes: their quantification as an index of oxidant stress status in vivo, Drug Metab Rev 32 (2000), 377-385.

[155] A. Mukherjee, L. Arnaud and J.A. Cooper, Lipid-dependent recruitment of neuronal Src to lipid rafts in the brain, $J$ Biol Chem 278 (2003), 40806-40814.

[156] B. Nathan, Y. Jiang, G. Wong, F. Shen, G. Brewer and R. Struble, Apolipoprotein E4 inhibits, and apolipoprotein E3 promotes neurite outgrowth in cultured adult mouse cortical neurons through the low-density lipoprotein receptor-related protein, Brain Research 928 (2002), 96-105.

[157] E.J. Neufeld, H. Sprecher, R.W. Evans and P.W. Majerus, Fatty acid structural requirements for activity of arachidonoylCoA synthetase, J Lipid Res 25 (1984), 288-293.

[158] J. Nimpf and W.J. Schneider, From cholesterol transport to signal transduction: low density lipoprotein receptor, very low 
density lipoprotein receptor, and apolipoprotein E receptor-2, Biochim Biophys Acta 1529 (2000), 287-298.

[159] E. Ninio, D. Tregouet, J.L. Carrier, D. Stengel, C. Bickel, C. Perret, H.J. Rupprecht, F. Cambien, S. Blankenberg and L. Tiret, Platelet-activating factor-acetylhydrolase and PAFreceptor gene haplotypes in relation to future cardiovascular event in patients with coronary artery disease, $\mathrm{Hum} \mathrm{Mol} \mathrm{Genet}$ 13 (2004), 1341-1351.

[160] K. Node, Y. Huo, X. Ruan, B. Yang, M. Spiecker, K. Ley, D.C. Zeldin and J.K. Liao, Anti-inflammatory properties of cytochrome P450 epoxygenase-derived eicosanoids, Science 285 (1999), 1276-1279.

[161] A.J. Nok, K.A. Esievo, A.I. Ukoha, C.O. Ikediobi, S. Ibrahim, O. Martins, B. Tekdek and J. Omage, Brain Na+ K+ ATPase and cholesterol in acute experimental trypanosomiasis, Cell Biochem Funct 10 (1992), 233-236.

[162] J. Nourooz-Zadeh, E.H. Liu, E. Anggard and B. Halliwell, F4-isoprostanes: a novel class of prostanoids formed during peroxidation of docosahexaenoic acid (DHA), Biochem Biophys Res Commun 242 (1998), 338-344.

[163] C. Nygren, H. von Holst, J.E. Mansson and P. Fredman, Increased levels of cholesterol esters in glioma tissue and surrounding areas of human brain, Br J Neurosurg 11 (1997), 216-220.

[164] K. Oishi, B. Zheng and J.F. Kuo, Inhibition of Na,K-ATPase and sodium pump by protein kinase $\mathrm{C}$ regulators sphingosine, lysophosphatidylcholine, and oleic acid, J Biol Chem 265 (1990), 70-75.

[165] A. Ojima, Y. Nakagawa, T. Sugiura, Y. Masuzawa and K. Waku, Selective transacylation of 1-Oalkylglycerophosphoethanolamine by docosahexaenoate and arachidonate in rat brain microsomes, J Neurochem 48 (1987), 1403-1410.

[166] K. Okuizumi, O. Onodera, Y. Namba, K. Ikeda, T. Yamamoto, K. Seki, A. Ueki, S. Nanko, H. Tanaka and H. Takahashi, Genetic association of the very low density lipoprotein (VLDL) receptor gene with sporadic Alzheimer's disease, Nat Genet 11 (1995), 207-209.

[167] H. Okuyama, W.E. Lands, F.D. Gunstone and J.A. Barve, Selective transfers of trans-ethylenic acids by acyl coenzyme A. Phospholipid acyltransferases, Biochemistry 11 (1972), 43924398.

[168] M.F. Oleksiak, S. Wu, C. Parker, S.I. Karchner, J.J. Stegeman and D.C. Zeldin, Identification, functional characterization, and regulation of a new cytochrome $\mathrm{P} 450$ subfamily, the CYP2Ns, J Biol Chem 275 (2000), 2312-2321.

[169] F.W. Pfrieger, Outsourcing in the brain: do neurons depend on cholesterol delivery by astrocytes? Bioessays 25 (2003), $72-78$.

[170] G. Pinna, R.C. Agis-Balboa, M.S. Doueiri, A. Guidotti and E. Costa, Brain neurosteroids in gender-related aggression induced by social isolation, Crit Rev Neurobiol 16 (2004), $75-82$.

[171] M. Pulfer and R.C. Murphy, Electrospray mass spectrometry of phospholipids, Mass Spectrom Rev 22 (2003), 332-364.

[172] M.K. Pulfer, K. Harrison and R.C. Murphy, Direct electrospray tandem mass spectrometry of the unstable hydroperoxy bishemiacetal product derived from cholesterol ozonolysis, $J$ Am Soc Mass Spectrom 15 (2004), 194-202.

[173] K. Qi, M. Hall and R.J. Deckelbaum, Long-chain polyunsaturated fatty acid accretion in brain, Curr Opin Clin Nutr Metab Care 5 (2002), 133-138.

[174] G.B. Quistad, C. Barlow, C.J. Winrow, S.E. Sparks and J.E. Casida, Evidence that mouse brain neuropathy target esterase is a lysophospholipase, Proc Natl Acad Sci USA 100 (2003), 7983-7987.

[175] S. Ramanadham, F. Hsu, S. Zhang, A. Bohrer, Z. Ma and J. Turk, Electrospray ionization mass spectrometric analyses of phospholipids from INS-1 insulinoma cells: comparison to pancreatic islets and effects of fatty acid supplementation on phospholipid composition and insulin secretion, Biochimica et Biophysica Acta (BBA)/Molecular and Cell Biology of Lipids 1484 (2000), 251-266.

[176] S.I. Rapoport, In vivo fatty acid incorporation into brain phospholipids in relation to signal transduction and membrane remodeling, Neurochem Res 24 (1999), 1403-1415.

[177] T.S. Reddy and N.G. Bazan, Arachidonic acid, stearic acid, and diacylglycerol accumulation correlates with the loss of phosphatidylinositol 4,5-bisphosphate in cerebrum 2 seconds after electroconvulsive shock: complete reversion of changes 5 minutes after stimulation, J Neurosci Res 18 (1987), 449455.

[178] P.C. Reid, N. Sakashita, S. Sugii, Y. Ohno-Iwashita, Y. Shimada, W.F. Hickey and T.Y. Chang, A novel cholesterol stain reveals early neuronal cholesterol accumulation in the Niemann-Pick type C1 mouse brain, J Lipid Res 45 (2004), 582-591.

[179] L. Riboni, P. Viani, R. Bassi, P. Giussani and G. Tettamanti, Basic fibroblast growth factor-induced proliferation of primary astrocytes. evidence for the involvement of sphingomyelin biosynthesis, J Biol Chem 276 (2001), 12797-12804.

[180] L.J. Roberts, C.J. Brame, Y. Chen and J.D. Morrow, Novel eicosanoids. Isoprostanes and related compounds, Methods Mol Biol 120 (1999), 257-285.

[181] L.J. Roberts, T.J. Montine, W.R. Markesbery, A.R. Tapper, P. Hardy, S. Chemtob, W.D. Dettbarn and J.D. Morrow, Formation of isoprostane-like compounds (neuroprostanes) in vivo from docosahexaenoic acid, J Biol Chem 273 (1998), 1360513612.

[182] K.A. Rose, G. Stapleton, K. Dott, M.P. Kieny, R. Best, M. Schwarz, D.W. Russell, I. Bjorkhem, J. Seckl and R. Lathe, Cyp7b, a novel brain cytochrome P450, catalyzes the synthesis of neurosteroids 7alpha-hydroxy dehydroepiandrosterone and 7alpha-hydroxy pregnenolone, Proc Natl Acad Sci USA 94 (1997), 4925-4930.

183] C.A. Ross, M.W. MacCumber, C.E. Glatt and S.H. Snyder, Brain phospholipase C isozymes: differential mRNA localizations by in situ hybridization, Proc Natl Acad Sci USA $\mathbf{8 6}$ (1989), 2923-2927.

[184] F. Sadeghlar, K. Sandhoff and G. Echten-Deckert, Cell type specific localization of sphingomyelin biosynthesis, FEBS Lett 478 (2000), 9-12.

[185] J. Sakai, A. Hoshino, S. Takahashi, Y. Miura, H. Ishii, H. Suzuki, Y. Kawarabayasi and T. Yamamoto, Structure, chromosome location, and expression of the human very low density lipoprotein receptor gene, J Biol Chem 269 (1994), 2173 2182.

[186] S. Salvati, L. Attorri, C. Avellino, A. Di Biase and M. Sanchez, Diet, lipids and brain development, Dev Neurosci 22 (2000), 481-487.

[187] M. Schumacher, S. Weill-Engerer, P. Liere, F. Robert, R.J. Franklin, L.M. Garcia-Segura, J.J. Lambert, W. Mayo, R.C. Melcangi, A. Parducz, U. Suter, C. Carelli, E.E. Baulieu and Y. Akwa, Steroid hormones and neurosteroids in normal and pathological aging of the nervous system, Prog Neurobiol 71 (2003), 3-29. 
[188] D. Seidel, R. Buck, R. Heipertz and H. Pilz, Cerebrospinal fluid lipids in demyelinating disease. I. Sphingolipids, J Neurol 222 (1980), 171-176.

[189] C.N. Serhan, J.Z. Haeggstrom and C.C. Leslie, Lipid mediator networks in cell signaling: update and impact of cytokines, FASEB J 10 (1996), 1147-1158.

[190] S. Sharma and S.C. Sharma, An update on eicosanoids and inhibitors of cyclooxygenase enzyme systems, Indian J Exp Biol 35 (1997), 1025-1031.

[191] K. Shibuya, N. Takata, Y. Hojo, A. Furukawa, N. Yasumatsu, T. Kimoto, T. Enami, K. Suzuki, N. Tanabe, H. Ishii, H. Mukai, T. Takahashi, T.A. Hattori and S. Kawato, Hippocampal cytochrome P450s synthesize brain neurosteroids which are paracrine neuromodulators of synaptic signal transduction, Biochim Biophys Acta 1619 (2003), 301-316.

[192] S. Shimohama, Y. Sasaki, S. Fujimoto, S. Kamiya, T. Taniguchi, T. Takenawa and J. Kimura, Phospholipase C isozymes in the human brain and their changes in Alzheimer's disease, Neuroscience 82 (1998), 999-1007.

[193] H. Shogomori and A.H. Futerman, Cholesterol depletion by methyl-beta-cyclodextrin blocks cholera toxin transport from endosomes to the Golgi apparatus in hippocampal neurons, $J$ Neurochem 78 (2001), 991-999.

[194] A.P. Simopoulos, Omega-3 fatty acids in health and disease and in growth and development, Am J Clin Nutr 54 (1991), $438-463$.

[195] W.L. Smith, The eicosanoids and their biochemical mechanisms of action, Biochem J 259 (1989), 315-324.

[196] M. Soderberg, C. Edlund, I. Alafuzoff, K. Kristensson and G. Dallner, Lipid composition in different regions of the brain in Alzheimer's disease/senile dementia of Alzheimer's type, $J$ Neurochem 59 (1992), 1646-1653.

[197] W.C. Song, C.D. Funk and A.R. Brash, Molecular cloning of an allene oxide synthase: a cytochrome P450 specialized for the metabolism of fatty acid hydroperoxides, Proc Natl Acad Sci USA 90 (1993), 8519-8523.

[198] G.C. Sparagna, C.A. Johnson, S.A. McCune, R.L. Moore and R.C. Murphy, Quantitation of cardiolipin molecular species in spontaneously hypertensive heart failure rats using electrospray ionization mass spectrometry, J Lipid Res (2005).

[199] H. Sprecher, An update on the pathways of polyunsaturated fatty acid metabolism, Curr Opin Clin Nutr Metab Care 2 (1999), 135-138.

[200] G. Staneva, M.I. Angelova and K. Koumanov, Phospholipase $\mathrm{A}_{2}$ promotes raft budding and fission from giant liposomes, Chem Phys Lipids 129 (2004), 53-62.

[201] D.T. Stephenson, J.V. Manetta, D.L. White, X.G. Chiou, L. Cox, B. Gitter, P.C. May, J.D. Sharp, R.M. Kramer and J.A. Clemens, Calcium-sensitive cytosolic phospholipase $\mathrm{A}_{2}$ $\left(\mathrm{cPLA}_{2}\right)$ is expressed in human brain astrocytes, Brain Res 637 (1994), 97-105.

[202] P. Strazzullo, F. Lamenza, A. Postiglione, L.A. Ferrara, D. Mansi and S. Montefusco, Abnormal cholesterol distribution in plasma lipoproteins of male patients with ischemic brain disease, Acta Neurol (Napoli) 3 (1981), 695-700.

[203] P.V. Subbaiah, J.J. Albers, C.H. Chen and J.D. Bagdade Low density lipoprotein-activated lysolecithin acylation by human plasma lecithin-cholesterol acyltransferase. Identity of lysolecithin acyltransferase and lecithin-cholesterol acyltransferase, J Biol Chem 255 (1980), 9275-9280.

[204] G.Y. Sun, J. Xu, M.D. Jensen and A. Simonyi, Phospholipase $\mathrm{A}_{2}$ in the central nervous system: implications for neurodegenerative diseases, J Lipid Res 45 (2004), 205-213.
[205] Y.X. Sun, K. Tsuboi, Y. Okamoto, T. Tonai, M. Murakami, I. Kudo and N. Ueda, Biosynthesis of anandamide and Npalmitoylethanolamine by sequential actions of phospholipase $\mathrm{A}_{2}$ and lysophospholipase D, Biochem J 380 (2004), 749-756.

[206] L. Svennerholm, K. Bostrom, B. Jungbjer and L. Olsson, Membrane lipids of adult human brain: lipid composition of frontal and temporal lobe in subjects of age 20 to 100 years, $J$ Neurochem 63 (1994), 1802-1811.

[207] R. Taguchi, J. Hayakawa, Y. Takeuchi and M. Ishida, Twodimensional analysis of phospholipids by capillary liquid chromatography/electrospray ionization mass spectrometry, $J$ Mass Spectrom 35 (2000), 953-966.

[208] K. Talbot, R.A. Young, C. Jolly-Tornetta, V.M. Lee, J.Q. Trojanowski and B.A. Wolf, A frontal variant of Alzheimer's disease exhibits decreased calcium- independent phospholipase $\mathrm{A}_{2}$ activity in the prefrontal cortex, Neurochem Int 37 (2000), $17-31$.

[209] Y. Tashiro, T. Yamazaki, Y. Shimada, Y. Ohno-Iwashita and K. Okamoto, Axon-dominant localization of cell-surface cholesterol in cultured hippocampal neurons and its disappearance in Niemann-Pick type C model cells, Eur J Neurosci 20 (2004), 2015-2021.

[210] A. Tokumura, Physiological and pathophysiological roles of lysophosphatidic acids produced by secretory lysophospholipase D in body fluids, Biochimica et Biophysica Acta (BBA)/Molecular and Cell Biology of Lipids 1582 (2002), 1825.

211] A.D. Tselepis and C.M. John, Inflammation, bioactive lipids and atherosclerosis: potential roles of a lipoprotein-associated phospholipase $\mathrm{A}_{2}$, platelet activating factor-acetylhydrolase, Atheroscler Suppl 3 (2002), 57-68.

[212] K. Tsutsui and K. Ukena, Neurosteroids in the cerebellar Purkinje neuron and their actions (review), Int J Mol Med 4 (1999), 49-56.

213] K. Tsutsui, K. Ukena, M. Usui, H. Sakamoto and M. Takase, Novel brain function: biosynthesis and actions of neurosteroids in neurons, Neurosci Res 36 (2000), 261-273.

[214] R. Uauy, D.R. Hoffman, P. Peirano, D.G. Birch and E.E. Birch, Essential fatty acids in visual and brain development, Lipids 36 (2001), 885-895.

[215] S.M. van der, H.H. Hansen, W.B. Veldhuis, P.R. Bar, K. Nicolay, G.A. Veldink, J.F. Vliegenthart and H.S. Hansen, Biosynthesis of endocannabinoids and their modes of action in neurodegenerative diseases, Neurotox Res 5 (2003), 183-200.

[216] D.E. Vance, C.J. Walkey and Z. Cui, Phosphatidylethanolamine N-methyltransferase from liver, Biochim Biophys Acta 1348 (1997), 142-150.

[217] J.E. Vance, H. Hayashi and B. Karten, Cholesterol homeostasis in neurons and glial cells, Semin Cell Dev Biol 16 (2005), 193-212.

[218] A. Wang and E. Dennis, Mammalian lysophospholipases, Biochimica et Biophysica Acta (BBA)/Molecular and Cell Biology of Lipids 1439 (1999), 1-16.

[219] X. Wang, Phospholipase D in hormonal and stress signaling, Current Opinion in Plant Biology 5 (2002), 408-414.

[220] H. Watanabe, M. Yamazaki, H. Miyazaki, C. Arikawa, K. Itoh, T. Sasaki, T. Maehama, M.A. Frohman and Y. Kanaho, Phospholipase D2 functions as a downstream signaling molecule of MAP kinase pathway in L1-stimulated neurite outgrowth of cerebellar granule neurons, J Neurochem $\mathbf{8 9}$ (2004), 142-151.

[221] M. Wender, Z. Adamczewska-Goncerzewicz, J. Szczech and A. Godlewski, Myelin lipids in aging human brain, Neurochem Pathol 8 (1988), 121-130. 
[222] K. Winkler, B.R. Winkelmann, H. Scharnagl, M.M. Hoffmann, A.B. Grawitz, M. Nauck, B.O. Bohm and W. Marz, Platelet-activating factor acetylhydrolase activity indicates angiographic coronary artery disease independently of systemic inflammation and other risk factors: the Ludwigshafen Risk and Cardiovascular Health Study, Circulation 111 (2005), 980-987.

[223] G. Wolfbauer, J.J. Albers and J.F. Oram, Phospholipid transfer protein enhances removal of cellular cholesterol and phospholipids by high-density lipoprotein apolipoproteins, Biochim Biophys Acta 1439 (1999), 65-76.

[224] B. Wolozin, J. Brown III, C. Theisler and S. Silberman, The cellular biochemistry of cholesterol and statins: insights into the pathophysiology and therapy of Alzheimer's disease, CNS Drug Rev 10 (2004), 127-146.

[225] D.A. Wolters, M.P. Washburn and J.R. Yates, III, An automated multidimensional protein identification technology for shotgun proteomics, Anal Chem 73 (2001), 5683-5690.

[226] W.G. Wood, F. Schroeder, N.A. Avdulov, S.V. Chochina and U. Igbavboa, Recent advances in brain cholesterol dynamics: transport, domains, and Alzheimer's disease, Lipids 34 (1999), 225-234.

[227] W.G. Wood, F. Schroeder, U. Igbavboa, N.A. Avdulov and S.V. Chochina, Brain membrane cholesterol domains, aging and amyloid beta-peptides, Neurobiol Aging 23 (2002), 685694.

[228] L.C. Wright, K.L. Obbink, E.J. Delikatny, R.T. Santangelo and T.C. Sorrell, The origin of $1 \mathrm{H}$ NMR-visible triacylglycerol in human neutrophils. Highfatty acid environments result in preferential sequestration of palmitic acid into plasma membrane triacylglycerol, Eur J Biochem 267 (2000), 68-78.

[229] R.L. Wykle and J.M. Schremmer, A lysophospholipase D pathway in the metabolism of ether-linked lipids in brain microsomes, J Biol Chem 249 (1974), 1742-1746.

[230] Z. Xie, W.T. Ho, R. Spellman, S. Cai and J.H. Exton, Mech- anisms of regulation of phospholipase D1 and D2 by the heterotrimeric G proteins G13 and Gq, J Biol Chem 277 (2002), 11979-11986.

[231] Y. Yamada and M. Yokota, Roles of plasma plateletactivating factor acetylhydrolase in allergic, inflammatory, and atherosclerotic diseases, Jpn Circ J 62 (1998), 328-335.

[232] S. Yehuda, S. Rabinovitz, L. Carasso and I. Mostofsky, The role of polyunsaturated fatty acids in restoring the aging neuronal membrane, Neurobiology of Aging 23 (2002), 843-853.

[233] D.C. Zeldin, J. Foley, J. Ma, J.E. Boyle, J.M. Pascual, C.R. Moomaw, K.B. Tomer, C. Steenbergen and S. Wu, CYP2J subfamily P450s in the lung: expression, localization, and potential functional significance, Mol Pharmacol 50 (1996), 1111-1117.

[234] D.C. Zeldin, C.R. Moomaw, N. Jesse, K.B. Tomer, J. Beetham, B.D. Hammock and S. Wu, Biochemical characterization of the human liver cytochrome $\mathrm{P} 450$ arachidonic acid epoxygenase pathway, Arch Biochem Biophys 330 (1996), 8796.

[235] K.A. Zemski Berry and R.C. Murphy, Free radical oxidation of plasmalogen glycerophosphocholine containing esterified docosahexaenoic acid: structure determination by mass spectrometry, Antioxid Redox Signal 7 (2005), 157-169.

[236] Y. Zhang, P. Huang, G. Du, Y. Kanaho, M.A. Frohman and S.E. Tsirka, Increased expression of two phospholipase D isoforms during experimentally induced hippocampal mossy fiber outgrowth, Glia 46 (2004), 74-83.

[237] Y. Zou, D. Hu, X. Yang, X. Jia, L. Wang, L. Cui, X. Liu, M. Gao, Y. Wei and Z. Xu, Relationships among apolipoprotein A1 gene polymorphisms, lipid levels and coronary atherosclerosis disease, Chin Med J (Engl) 116 (2003), 665-668.

[238] G.S. Zubenko, S. Stiffler, S. Stabler, U. Kopp, H.B. Hughes, B.M. Cohen and J. Moossy, Association of the apolipoprotein E epsilon 4 allele with clinical subtypes of autopsy-confirmed Alzheimer's disease, Am J Med Genet 54 (1994), 199-205. 


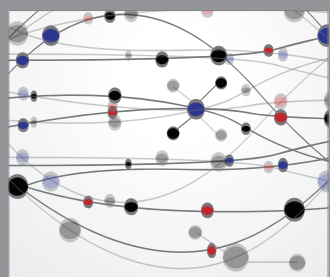

The Scientific World Journal
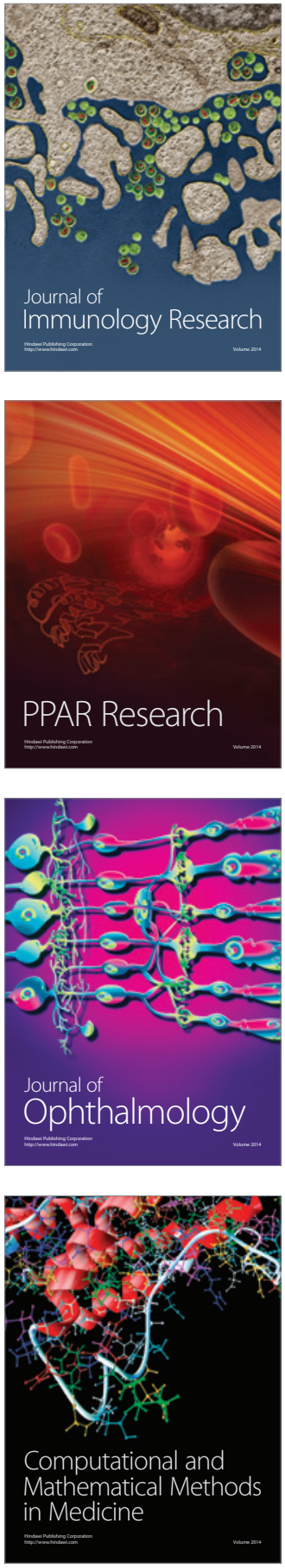

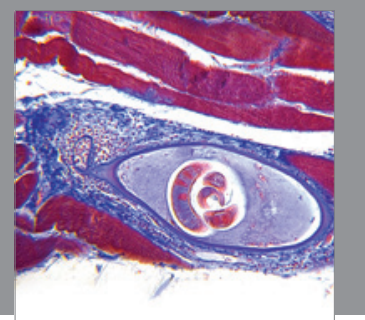

Gastroenterology

Research and Practice
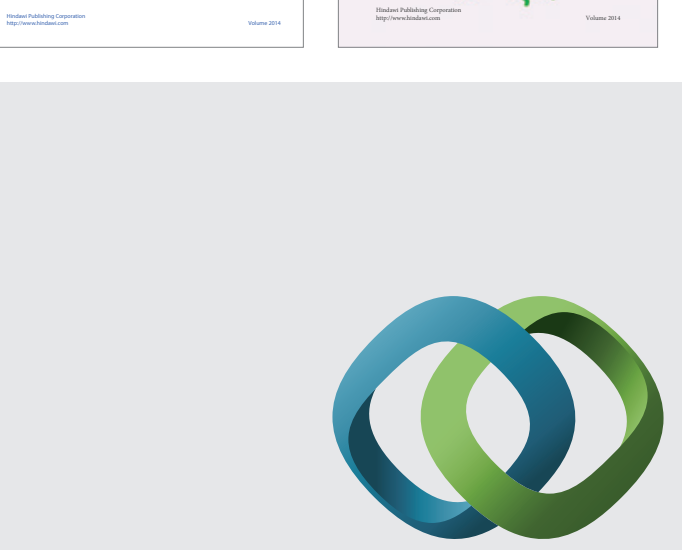

\section{Hindawi}

Submit your manuscripts at

http://www.hindawi.com
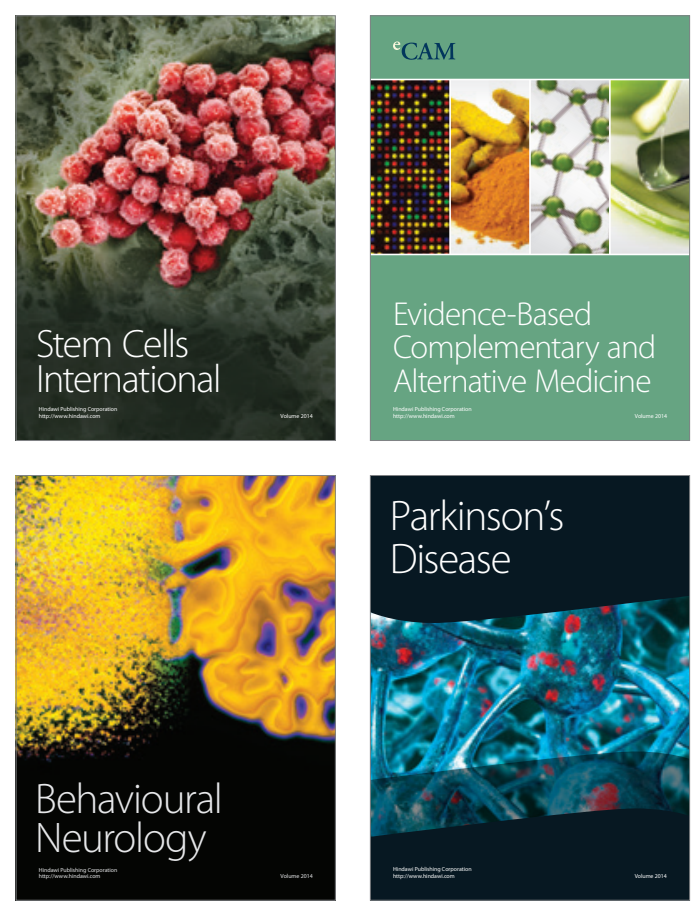

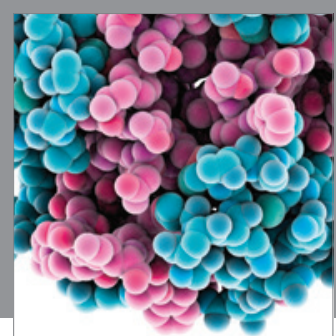

Journal of
Diabetes Research

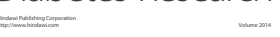

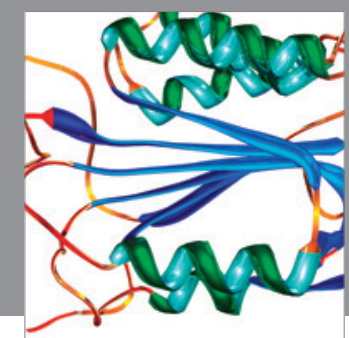

Disease Markers
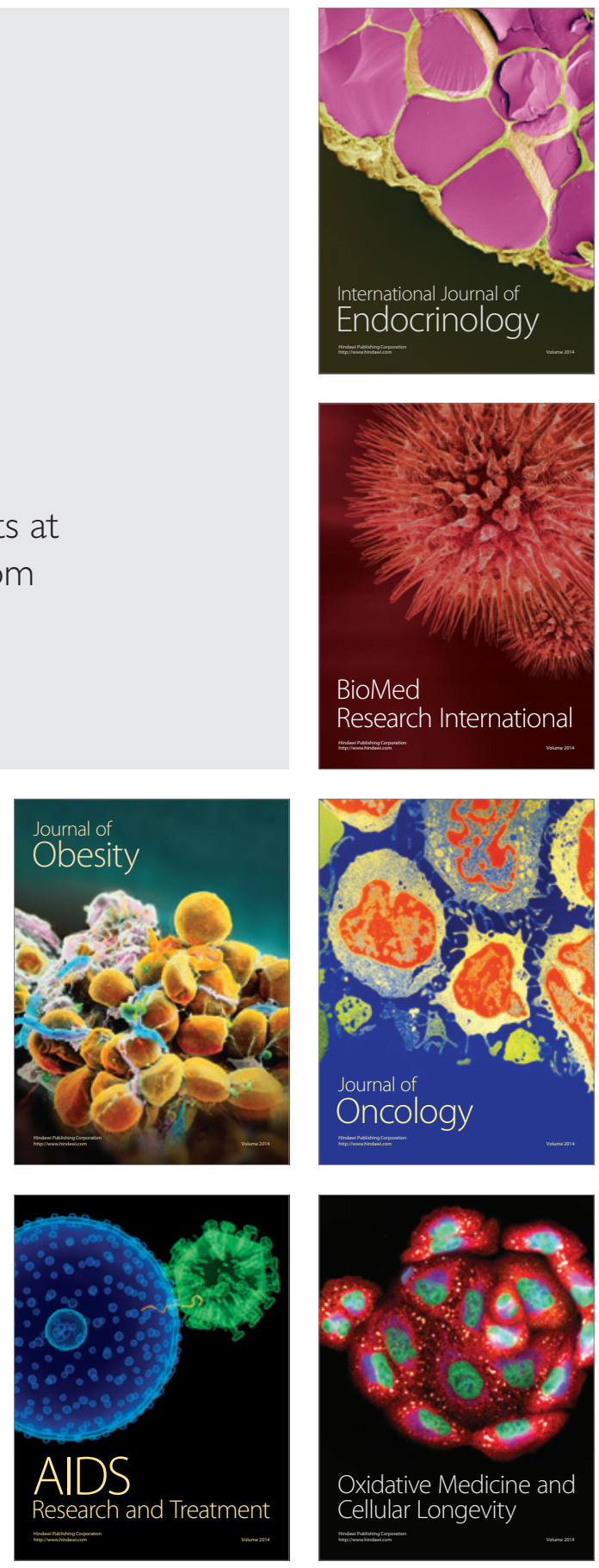